\title{
a3 Integrin of Cell-Cell Contact Mediates Kidney Fibrosis by Integrin-Linked Kinase in Proximal Tubular E-Cadherin Deficient Mice
}

\author{
Guoping Zheng, ${ }^{*}$ Jianlin Zhang, ${ }^{* \dagger}$ Hong Zhao, ${ }^{* \dagger}$ Hailong Wang, ${ }^{* \dagger}$ Min Pang, ${ }^{* \ddagger}$ Xi Qiaoo, ${ }^{\star \S}$ So R. Lee, ${ }^{*}$ Tzu-Ting Hsu, ${ }^{*}$
} Thian K. Tan, ${ }^{*}$ J. Guy Lyons, ${ }^{\natural}$ Ye Zhao, ${ }^{*}$ Xinrui Tian,, David A.F. Loebel, ${ }^{* *}$ Isabella Rubera, ${ }^{\dagger \dagger}$ Michel Tauc, ${ }^{\dagger \dagger}$ Ya Wang, ${ }^{*}$ Yiping Wang, ${ }^{*}$ Yuan M. Wang, ${ }^{\ddagger}$ Qi Cao, ${ }^{*}$ Changqi Wang, ${ }^{*}$ Vincent W.S. Lee, ${ }^{*}$ Stephen I. Alexander, ${ }^{\ddagger}$ Patrick P.L. Tam, ${ }^{* *}$ and David C.H. Harris*

\begin{abstract}
From the Centre for Transplantation and Renal Research, * Westmead Millennium Institute, University of Sydney, Sydney, Australia; the Department of Biochemistry and Molecular Biology, ${ }^{\dagger}$ Shanxi Medical University, Taiyuan, People’s Republic of China; the Department of Respiratory Medicine, ${ }^{\ddagger}$ the First

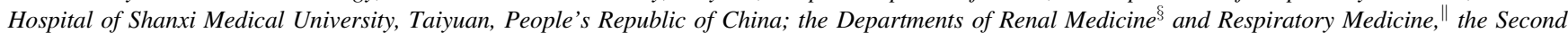
Hospital of Shanxi Medical University, Taiyuan, People's Republic of China; the Sydney Head and Neck Cancer Institute, "Sydney Cancer Centre, Royal Prince Alfred Hospital, Centenary Institute and Department of Dermatology, University of Sydney, Sydney, Australia; the Embryology Unit,** Children's Medical Research Institute, and Sydney Medical School, University of Sydney, Sydney, Australia; the Laboratory of Molecular Physio-Medicine, National Centre for Scientific Research, ${ }^{\dagger \dagger}$ University of Nice-Sophia Antipolis, Parc Valrose, Nice, France; and the Centre for Kidney Research, ${ }^{\ddagger \ddagger}$ Children’s Hospital at Westmead, Sydney, Australia
\end{abstract}

Accepted for publication March 17, 2016.

Address correspondence to Guoping Zheng, M.D., Ph.D., Centre for Transplantation and Renal Research, Westmead Millennium Institute, University of Sydney, Sydney, NSW 2145, Australia. E-mail: guoping.zheng@sydney.edu.au.

\begin{abstract}
Loss of E-cadherin marks a defect in epithelial integrity and polarity during tissue injury and fibrosis. Whether loss of E-cadherin plays a causal role in fibrosis is uncertain. $\alpha 3 \beta 1$ Integrin has been identified to complex with E-cadherin in cell-cell adhesion, but little is known about the details of their cross talk. Herein, E-cadherin gene (Cdh1) was selectively deleted from proximal tubules of murine kidney by Sglt2Cre. Ablation of E-cadherin up-regulated $\alpha 3 \beta 1$ integrin at cell-cell adhesion. E-cadherin-deficient proximal tubular epithelial cell displayed enhanced transforming growth factor- $\beta 1$-induced $\alpha$-smooth muscle actin ( $\alpha$-SMA) and vimentin expression, which was suppressed by siRNA silencing of $\alpha 3$ integrin, but not $\beta 1$ integrin. Up-regulation of transforming growth factor- $\beta 1$-induced $\alpha$-SMA was mediated by an $\alpha 3$ integrin-dependent increase in integrin-linked kinase (ILK). Src phosphorylation of $\beta$-catenin and consequent $\mathrm{p}$ - $\beta$-catenin- $Y 654 / \mathrm{p}$-Smad2 transcriptional complex underlies the transcriptional upregulation of ILK. Kidney fibrosis after unilateral ureteric obstruction or ischemia reperfusion was increased in proximal tubule E-cadherin-deficient mice in comparison to that of E-cadherin intact control mice. The exacerbation of fibrosis was explained by the $\alpha 3$ integrin-dependent increase of ILK, $\beta$-catenin nuclear translocation, and $\alpha$-SMA/proximal tubular-specific Cre double positive staining in proximal tubular epithelial cell. These studies delineate a nonconventional integrin/ILK signaling by $\alpha 3$ integrin-dependent Src/p- $\beta$-catenin-Y654/p-Smad2-mediated up-regulation of ILK through which loss of E-cadherin leads to kidney fibrosis. (Am J Pathol 2016, 186: 1847-1860; http://dx.doi.org/ 10.1016/j.ajpath.2016.03.015)
\end{abstract}

Fibrosis is a key component of parenchymal destruction in all chronic diseases leading to organ failure. ${ }^{1}$ Loss of E-cadherin marks a defect in epithelial integrity and polarity during tissue injury and fibrosis, but a causative role for E-cadherin in fibrosis has never been clearly defined. Previous in vitro studies in cancer all suggest a protective role for E-cadherin against transforming growth factor (TGF)- $\beta$
Supported by the National Health and Medical Research Council (NHMRC) of Australia grants 632688 (D.H. and G.Z.) and 1026232 (J.L.), a NHMRC Peter Doherty Fellowship (G.Z.), and University of Sydney New Staff/Early Career Researcher grant (G.Z.), and a NHMRC Senior Principal Research Fellow grant 1003100 (P.P.L.T.).

G.Z., J.Z., H.Z., H.W., and M.P. contributed equally to this work.

Disclosures: None declared. 
signaling in epithelial-mesenchymal transition (EMT), ${ }^{2-4}$ whereas EMT-like TGF- $\beta$-induced profibrotic changes (type II EMT) in epithelial cells contribute to organ fibrosis. ${ }^{5,6}$ In contrast to previous findings, E-cadherin was recently reported to assist $\alpha 3 \beta 1$ integrin-mediated profibrotic changes and fibrosis. ${ }^{7}$ More important, the controversial roles of E-cadherin have not been tested in vivo in fibrotic disease in which the EMT differs from that of cancer and development. ${ }^{5,8}$

E-cadherin is a single-pass transmembrane cell-cell adhesion molecule that participates in the formation of adherens junctions, and other epithelial cell connections, including tight junctions. ${ }^{9,10}$ In addition to its major role in the establishment and maintenance of epithelial cell polarity, E-cadherin has been implicated in transmembrane signal transduction. ${ }^{11,12}$ Integrins, such as $\alpha 3 \beta 1$, are primarily responsible for cell-matrix interaction at the basal side of epithelia ${ }^{13}$ and have also been implicated in E-cadherin-mediated cell-cell adhesion. ${ }^{14,15}$ More important, integrin activation imparts growth factor receptor-mediated intracellular signal transduction. ${ }^{16,17} \alpha 3$ Integrin null lung epithelial cells did not undergo profibrotic changes in response to TGF- $\beta{ }^{7}$ whereas mice without lung epithelial $\alpha 3$ integrin were protected against bleomycininduced fibrosis. ${ }^{18,19}$ In contrast to previous findings, E-cadherin was suggested to assist $\alpha 3 \beta 1$ integrindependent profibrotic changes. ${ }^{7}$ Nevertheless, the details of the cross talk between E-cadherin and $\alpha 3 \beta 1$ integrin in the cell-cell adhesion compartment remain unclear. Although integrin-linked kinase (ILK) has been proved to be a key mediator of TGF- $\beta$-induced fibrosis, ${ }^{20-22}$ the reported profibrotic role of $\alpha 3$ integrin has never been linked to ILK. Little is known about how ILK expression is up-regulated by TGF- $\beta$ in fibrosis. More important, whether E-cadherin or loss of E-cadherin contributes to TGF- $\beta$-induced fibrosis remains uncertain.

By using the Cre-loxP system, ${ }^{23}$ E-cadherin has been conditionally depleted in several types of epithelial cell. Previous studies mainly focused on roles of E-cadherin in tissue differentiation and maintenance of cell-cell adhesion junctions, ${ }^{24}$ whereas the impact of loss of E-cadherin on tissue fibrosis has not been examined. Herein, we inactivated the E-cadherin gene $(C d h l)$ specifically in murine kidney proximal tubules using $\mathrm{Sglt} 2 \mathrm{Cre}^{25}$ to explore the role of E-cadherin in kidney fibrosis in the context of unilateral ureteral obstruction (UUO). We show that loss of Ecadherin results in the up-regulation of $\alpha 3 \beta 1$ integrin in the proximal tubule, whereas kidney morphology, expression of cell adhesion factors, such as $\mathrm{N}$-cadherin and zonular occludens 1 (ZO-1), and kidney function are not changed. However, kidney fibrosis is exacerbated in the proximal tubule-specific E-cadherin-deficient mice after UUO. This is explained by an up-regulation of $\alpha 3 \beta 1$ integrin at cell-cell adhesion of E-cadherin-deficient proximal tubules, and an $\alpha 3$ integrin-dependent enhancement of TGF- $\beta$-induced profibrotic changes via p- $\beta$-catenin-Y654/p-Smad2 upregulation of ILK.

\section{Materials and Methods}

\section{Ethics Statement}

All animal experiments described herein were approved by the Animal Ethics Committee of Western Sydney Local Health District and performed in strict accordance with guidelines of the committee.

\section{Generation of Conditional E-Cadherin Knockout Mouse}

Mice with conditional knockout of E-cadherin in renal proximal tubular epithelial cells (PTECs) only were gener-

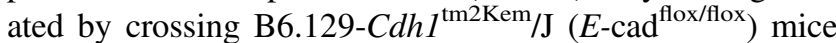
sequentially with B6.129-CMV Cre $(C M V . C r e)$, B6.D2Sglt2 $^{\text {Cre }}$ (Sglt2.Cre) mice ${ }^{25}$ and then backcrossed to the $E$-cad floxfflox mice (Supplemental Figure S1). B6.129-

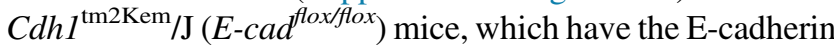
(Cdhl) gene (exon 6 to 10) flanked by two loxP sequence, were purchased from Jackson Laboratories (Bar Harbor, ME). B6.D2-Sglt2 ${ }^{\mathrm{Cre}}$ (Sglt2.Cre) mice specifically express Cre recombinase in kidney proximal tubule. B6.129-CMV $V^{\text {Cre }}$ (CMV.Cre) mice carrying an $\mathrm{X}$ chromosome-linked Cre driven by human cytomegalovirus minimal promoter were used as a general deleter. $E$-cad $d^{f l o x f l o x}$ mice were first crossed with CMV.Cre to generate $E-\mathrm{Cad}^{-1+}$; CMV.Cre. The Xlinked $C M V$.Cre was then removed by brother-sister crossing between $E-\mathrm{cad}^{-1+} ; C M V$.Cre and E-cad flox/+ mice to generate $E$ - $\mathrm{cad}^{-1+}$ mice. $E$-cad ${ }^{-1+}$ mice were then crossed with Sglt2.Cre to generate $E$-cad ${ }^{-/+} ;$Sglt2.Cre phenotype. The proximal tubule depletion of E-cadherin $\left(E-c a d^{-f f o x}\right.$; sglt2.Cre: mutant, knockout) was achieved by back-crossing the $E$-cad ${ }^{-1+} ;$ Sglt2.Cre with $E$-cad $d^{f l o x f l o x}$ mice. $E$-cad ${ }^{+/ f l o x}$; Sglt2.Cre littermates were used as control. By this method, selective depletion of E-cadherin from PTECs was achieved and the chance of a mosaic phenotype was minimized. Conditional E-cadherin-deficient and littermate control animals were on a mixed C57BL/6/129 genetic background.

\section{Genotyping}

The genotypes were determined with PCR primer sets: oIMR9338, 5'-GGGTCTCACCGTAGTCCTCA-3', and oIMR9339, 5'-GATCTTTGGGAGAGCAGTCG-3' for detection of $C d h 1^{f l o x}$ allele (Supplemental Figure S1C); cre forward primer, 5'-TCCTGGAAAATGCTTCTGTCCG-3', and cre reverse primer, 5'-CAGGGTGTTATAAGCAATCCC-3', for detection of Sglt2 cre allele (Supplemental Figure S1B); del forward primer, 5'-GAATTCTGAACATCATTATCAGTATTTA-3' ${ }^{\prime}$, and del reverse primer, $5^{\prime}$-TGACACATGCCTTTACTTTAGT- ${ }^{\prime}$, for detection of Ecadherin deletion allele $\left(E-\right.$ cad $\left.^{-}\right)$(Supplemental Figure S1A), and $C M V$ cre forward primer, 5'-CTGACCGTACACCAAAATTTGCCTG- $3^{\prime}$, and $C M V$ cre reverse primer, $5^{\prime}$-GATAATCGCGAACATCTTCAGGTTC-3', for detection of CMV.cre allele. 


\section{UUO Model}

UUO was performed by left proximal ureteral ligation under anesthesia, as described elsewhere. ${ }^{26}$ UUO mice were sacrificed 2 weeks after UUO. Both obstructed and contralateral unobstructed kidneys from PTEC E-cad ${ }^{-1-}$ and littermate control mice were harvested.

\section{IR Model}

Unilateral kidney ischemia reperfusion (IR) was induced by clamping left renal pedicles for 45 minutes under anesthesia (2\% isofluorane) of both PTEC $E-$ cad $^{-1-}$ and control mice. Mice were sacrificed to collect kidney tissue 3 weeks after IR.

\section{Renal Proximal Tubular Epithelial Cell Culture and Treatment}

Kidneys were excised, the capsules were removed, and washed in cold Dulbecco's modified Eagle's medium:Ham's F12; 1:1 v/v (Invitrogen, Carlsbad, CA). Primary tubular epithelial cells were obtained from the cortex of mouse kidney using established methods. ${ }^{27}$ The PTEC was further purified by cell sorting using antimegalin antibody. Isolated primary PTECs were cultured in complete $\mathrm{K} 1$ medium [Dulbecco's modified Eagle's medium:F12 containing $25 \mu \mathrm{g} /$ $\mathrm{mL}$ of epidermal growth factor (Sigma, St. Louis, MO), 25 $\mu \mathrm{mol} / \mathrm{L}$ of HEPES, and hormone mixture] with $5 \%$ fetal calf serum (Invitrogen) at $37^{\circ} \mathrm{C}$ with $5 \% \mathrm{CO}_{2}$ for 24 hours, and washed and cultured in serum-free complete $\mathrm{K} 1$ medium for 2 to 3 days before treatment with TGF- $\beta 1$. In experiments using TGF- $\beta 1$ treatment, subconfluent cultures of PTECs were rinsed with phosphate-buffered saline (PBS), the corresponding serum-supplemented media were replaced with respective serum-free media, and then treated with $5 \mathrm{ng} / \mathrm{mL}$ TGF- $\beta 1$ (Invitrogen) for 48 hours.

\section{Plasmid DNA and siRNA Transfection}

E-cadherin expression construct (wild-type E-cad) was made by cutting mouse E-cadherin ORF from plasmid moEcad/ BIISK1 (BglII) with EcoR V/NotI and inserting into the corresponding sites of pIRESneoGL2. Integrin $\alpha 3$ siRNA (sc-37120), integrin $\beta 1$ siRNA (sc-35675), ILK siRNA (sc35667), and control siRNA (sc-44230) were purchased from Santa Cruz Biotechnology (Dallas, TX). Plasmid DNA or siRNA transfection of $60 \%$ to $80 \%$ confluent cells was performed using Lipofectamine LTX and Lipofectamine RNAiMAX (Invitrogen), respectively, following the manufacturer's instructions. Medium was changed after 6 to 8 hours. Cells were analyzed 48 to 72 hours after transfection.

\section{Antibodies}

Mouse Lrp2/megalin polyclonal antibody, rabbit antiE-cadherin monoclonal antibody, rabbit anti- $\beta$-catenin antibody, rabbit anti-ZO-1 antibody, mouse anti-vimentin, rabbit anti- $\alpha$-smooth muscle actin ( $\alpha$-SMA) antibody, and rabbit phospho-glycogen synthetase kinase-3 $\beta$ (Ser9) antibody were purchased from Abcam (Cambridge, MA). Mouse anti-actin polyclonal antibody, rat anti-integrin $\beta 1$ antibody, and rabbit anti-integrin $\alpha 3$ monoclonal antibody were from Millipore (Darmstadt, Germany). Mouse antifibronectin was from Santa Cruz Biotechnology. Rabbit anti-ILK antibody, anti-mouse IgG, and anti-rabbit IgG, horseradish peroxidase-linked antibodies, and rabbit Cre monoclonal antibody were from Cell Signaling Technology (Danvers, MA), Alexa Fluor 546 goat anti-mouse IgG $(\mathrm{H}+\mathrm{L})$, and Alexa Fluor 488 goat anti-rabbit $\operatorname{IgG}(\mathrm{H}+\mathrm{L})$ were from Invitrogen.

\section{Coimmunoprecipitation}

Nuclear proteins were extracted using a NE-PER Nuclear and Cytoplasmic Extraction kit (Thermo Scientific, Waltham, MA), according to the manufacturer's instructions, and then quantified by BCA assay kit (Thermo Scientific). Coimmunoprecipitation (Co-IP) was performed using the Protein-G Immunoprecipitation Kit (Invitrogen). Briefly, $2 \mu \mathrm{g}$ of affinity-purified antibody was incubated with $50 \mu \mathrm{L}$ Protein-G agarose beads for 10 minutes at room temperature, after three times washes with antibody bind/wash buffer, 800 $\mu \mathrm{g}$ nuclear proteins were added for incubation at $4^{\circ} \mathrm{C}$ overnight. The agarose beads were collected by pulse centrifugation, the supernatant was discarded, and beads were washed three times with $200 \mu \mathrm{L}$ IP wash buffer. Finally, immunoprecipitated proteins were subjected to SDS-PAGE followed by Western blot with indicated primary antibody. Western blot analyses of nuclear proteins served as input.

\section{Western Blot Analysis}

Cells were lysed in Tris glycine SDS sample buffer (Gradipore, Frenchs Forest, Australia), and cell extracts were separated by NuPAGE $4 \%$ to $12 \%$ Bis-Tris gel (Invitrogen). Proteins were then transferred to polyvinylidene difluoride membranes (Millipore), blocked with 5\% skim milk in PBS, and probed with corresponding primary antibodies overnight at $4^{\circ} \mathrm{C}$. Membranes were washed and incubated with horseradish peroxidase-conjugated secondary antibody (Santa Cruz Biotechnology) for 40 minutes at room temperature. Proteins were finally visualized using enhanced chemiluminescence reagents (Amersham Bioscience, Piscataway, NJ). Protein expression was measured with Gel-Pro Analyzer image software version 3.1 (Informer Technologies, Madrid, Spain; http:// gel-pro-analyzer.software.informer.com/3.1) by quantifying the relative expression of target protein versus $\beta$-actin.

\section{Chromatin Immunoprecipitation Assays}

Chromatin immunoprecipitation assays were performed using a kit from Cell Signaling Technology, according to 
the protocol supplied. In brief, cells were fixed with $1 \%$ formaldehyde in PBS to cross-link chromatin. Cell lysates were prepared and digested by micrococcal nuclease to break chromatin DNA, ranging approximately 150 to 900 bp on average. After a preclearing step, IP was performed at $4{ }^{\circ} \mathrm{C}$ overnight with anti-smad 2 antibody or normal rabbit IgG (negative control antibody). Immune complexes were collected with protein-G magnetic beads. After extensive washing, the immunoprecipitated complexes were eluted and protein-DNA cross-links were reversed by incubating at $65^{\circ} \mathrm{C}$ for 2 hours. DNA was purified using proteinase $\mathrm{K}$ digestion and collected using DNA Clean-Up Column. For the smad binding site at position 247 of the mouse ILK promoter, the 219 and 289 region was amplified by realtime PCR with the primer pairs set: 5'-GCTGACACCACTCGGGAAAC-3' (forward) and 5'-AGAGGTGTCAGTGTGGGATG-3' (reverse). The amount of ILK promoter that was present in the IP and input fractions was calculated from the standard curve. The input represents $2 \%$ of the material used in the IP assay. The results were expressed as the IP/input ratios of the PCR products that were used for comparison.

\section{Histology and Immunohistochemistry}

For histology and immunohistochemistry, the kidneys were fixed in $10 \%$ neutral buffered formalin and embedded in paraffin. Microtome sections (4 to $5 \mu \mathrm{m}$ thick) were deparaffinized, rehydrated, and blocked with $3 \% \mathrm{H}_{2} \mathrm{O}_{2}$ in methanol $(\mathrm{v} / \mathrm{v})$ for 8 minutes. Antigen retrieval was performed using antigen deloaker (Biocare Medical, Concord, CA) for 10 minutes at $95^{\circ} \mathrm{C}$ for fibronectin and vimentin staining. For frozen kidney samples, cryosections were fixed for $10 \mathrm{mi}-$ nutes with cold methanol. Kidney tissue sections were blocked with $2 \%$ bovine serum albumin in PBS for 1 hour at room temperature and subjected to staining with primary antibodies. The sections were washed three times with PBS with $0.1 \%$ Tween-20 before incubation with their respective horseradish peroxidase-conjugated secondary antibodies in $2 \%$ bovine serum albumin in PBS for 40 minutes at room temperature or $4^{\circ} \mathrm{C}$ overnight. Antibody binding was visualized with 3'3-diaminobenzidine (Dako) and sections were counterstained with hematoxylin (Sigma). To assess interstitial fibrosis, Gomori trichrome and Sirius Red staining were performed.

For quantitation, stained specimens were scanned and analyzed with ScanScope digital scanner (Aperio, Oakleigh, Australia).

\section{Immunofluorescence Staining}

For indirect immunofluorescence staining, cells cultured on coverslips or kidney cryosections were fixed with cold methanol for 10 minutes at $-20^{\circ} \mathrm{C}$, then blocked with $2 \%$ bovine serum albumin in PBS for 1 hour at room temperature, followed by incubation with primary antibodies for 1 hour at room temperature or overnight at $4^{\circ} \mathrm{C}$. After washing with PBS, cells or cryosections were incubated with Alexa Fluor-488 or Texas Red conjugated secondary antibodies for 40 minutes at room temperature. They were then washed with PBS and counterstained with DAPI (Invitrogen) for 5 minutes before mounting with fluorescentmounting medium (Vector Laboratories, Burlingame, CA). Images were visualized and captured by a fluorescence microscope (Olympus BX51) or a Delta Vision microscope. A minimum of 10 consecutive nonoverlapping fields were taken at $\times 200$ magnification for each slide.

\section{Electron Microscopy}

Kidney specimens were fixed in modified Karnovsky's fixative buffer and $0.1 \mathrm{~mL} / \mathrm{L}$ 3-morpholinopropane1 -sulfonic acid buffer and then embedded in epoxy resin. Semithin and ultrathin sections were stained with uranyl acetate and lead citrate. All samples were examined in a Philips CM120 BioTWIN transmission EM (FEI) operated at $80 \mathrm{kV}$. Images were acquired using an SIS Morada digital camera (Soft Imaging Systems, Berlin, Germany) using the iTEM software suite.

\section{Renal Function Assay}

Renal function was assessed by the measurement of serum creatinine and urine albumin, creatinine, total protein, $\mathrm{K}^{+}$, $\mathrm{Na}^{+}, \mathrm{pH}$, and glucose, as described previously. ${ }^{28}$ All urine and blood specimens were examined by the Institute of Clinical Pathology and Medical Research (Westmead Hospital).

Creatinine clearance $(\mu \mathrm{L} /$ minute) $=$ (urine creatinine/ serum creatinine $) \times$ urine volume $(\mu \mathrm{L}) /[$ time (hours) $\times 60$ ]

\section{Real-Time Quantitative RT-PCR}

RNA was extracted from primary cultured PTECs using RNeasy Mini Kit (Qiagen, Valencia, CA). cDNA was synthesized using total RNA by Superscipt First strand synthesis system (Invitrogen). Real-Time Quantitative PCR was performed using following primer pairs: SNAIL 1, $5^{\prime}$ CTTGTGTCTGCACGACCTGT-3' (forward) and $5^{\prime}$ CTTCACATCCGAGTGGGTTT-3' (reverse); integrin $\alpha 3$, $5^{\prime}$-CCTCTTCGGCTACTCGGTC- $3^{\prime}$ (forward) and $5^{\prime}$ CCGGTTGGTATAGTCATCACCC- $3^{\prime}$ (reverse); integrin $\beta 1,5^{\prime}$-ATGCCAAATCTTGCGGAGAAT- $3^{\prime}$ (forward) and $5^{\prime}$-TTTGCTGCGATTGGTGACATT-3' (reverse); $\beta$-actin, $5^{\prime}$-GATTACTGCTCTGGCTCCTAGCA-3' (forward) and $5^{\prime}$-GCCACCGATCCACACAGAGT-3' (reverse); collagen I, 5'-GCGAAGGCAACAGTCGCT-3' (forward) and 5'CTTGGTGGTTTTGTATTCGATGAC- $3^{\prime}$ (reverse), and SYBR Green mastermix (Invitrogen) in Corbett Rotorgene 3000 Real-Time Thermo cycler. Housekeeping gene $\beta$-actin was used as endogenous control. 


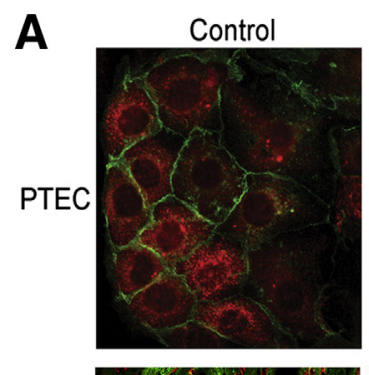

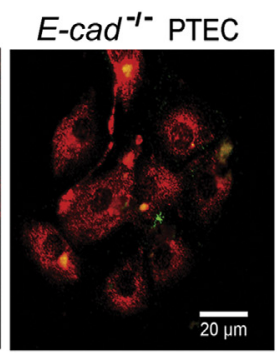
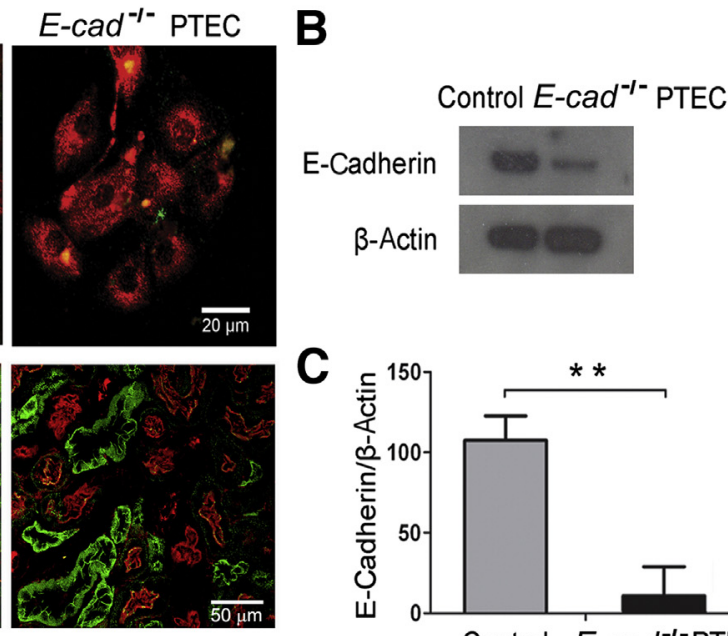

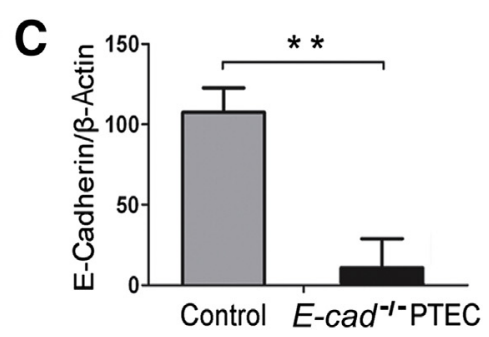

Figure 1 Deletion of E-cadherin by Sglt2.Cre activity in proximal tubular epithelial cells. A: Immunofluorescence staining of cultured proximal tubular epithelial cell (PTEC) from control and PTEC E-cad ${ }^{-1-}$ mice and kidney tissue stained for Ecadherin (green) and megalin (red), a PTEC marker. E-cadherin staining is absent from megalin-positive cultured PTEC and kidney proximal tubules of PTEC

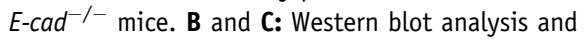
quantification of E-cadherin in lysates of PTEC isolated from control and PTEC E-cad ${ }^{-1-}$ mice. Data are shown as means \pm SD (C). $n=3$ (C). $* * P<0.01$. Scale bar $=20$ or $50 \mu \mathrm{m}(\mathbf{A})$.

\section{Statistical Analysis}

Results from at least three independent experiments were expressed as means $\pm \mathrm{SD}$. A $t$-test was used to determine the significance of differences between two groups, whereas the one-way analysis of variance was used for comparison of multiple groups. $P<0.05$ was considered significant.

\section{Results}

\section{Depletion of E-Cadherin by Sglt2.Cre Activity in PTECS}

PTEC-specific deletion of E-cadherin was generated by crossing E-cad $d^{f l o x f f l o x}\left(\mathrm{~B} 6.129-C d h l^{t m 2 K e m / J}\right)$ mice sequentially with general deletor CMV.Cre (B6.129-CMV ${ }^{\mathrm{Cre}}$ ) mice and PTEC-specific Sglt2.Cre (B6.D2-Sglt2 ${ }^{\mathrm{Cre}}$ ) mice and then

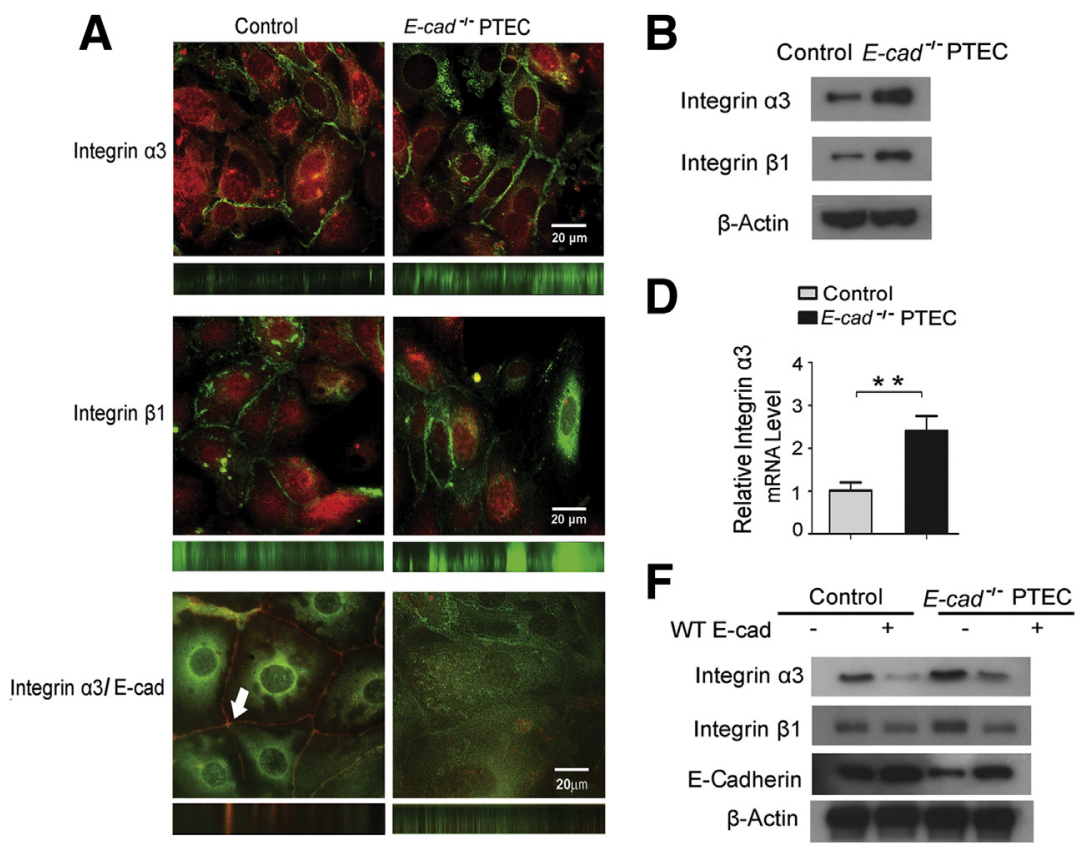

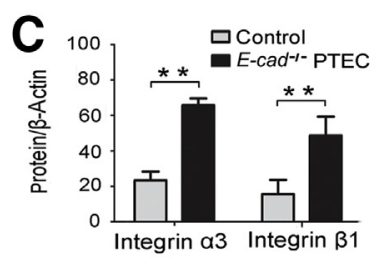

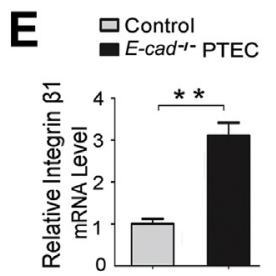

G

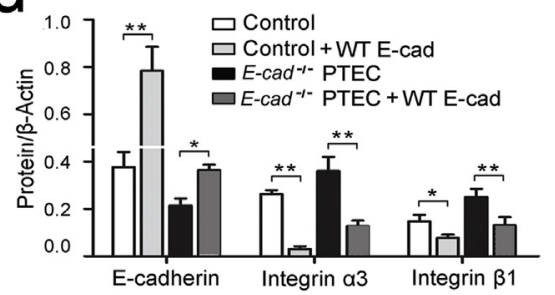

Figure 2 E-cadherin deletion in proximal tubular epithelial cell (PTEC) up-regulates expression of integrin $\alpha 3 \beta 1$. A: Confocal immunofluorescence images of XY (top panels) and XZ (bottom panels) sections of cultured control and E-cad ${ }^{-1-}$ PTEC stained for the PTEC marker megalin (red, top and middle panels), integrin $\alpha 3$ (green, top rows), $\beta 1$ (green, middle rows), and membrane $\alpha 3$ integrin (lower rows) (red)/E-cadherin (green) double staining (orange) at cellcell contact (indicated by arrow). Significant increase of $\alpha 3$ and $\beta 1$ integrin staining in E-cad ${ }^{-/}$PTEC are clearly shown by their XZ sections. B and C: Western blot analysis and quantification of integrin $\alpha 3$ and integrin $\beta 1$ in lysates of cultured control and E-cad ${ }^{-/-}$PTEC. D and E: Real-time PCR analysis and quantification of integrin $\alpha 3$ and integrin $\beta 1$ in cultured control and $E$-cad ${ }^{-1-}$ PTEC. $\mathbf{F}$ and $\mathbf{G}$ : Western blot analysis and quantification of integrin $\alpha 3$, integrin $\beta 1$, and E-cadherin in lysates of cultured control and $E$-cad ${ }^{-/}$PTEC transfected with or without wild-type E-cadherin (WT E-cad). Data are shown as means $\pm \mathrm{SD}$ (C-E and $\mathbf{G}) . n=3(\mathbf{C}-\mathbf{E}$ and $\mathbf{G}) .{ }^{*} P<0.05,{ }^{*} * P<0.01$. Scale bar $=20 \mu \mathrm{m}(\mathbf{A})$. 
backcrossing to $E$-cad floxflox mice (Supplemental Figure S2). To prove ablation of E-cadherin in PTEC in conditional E-cadherin mutant mice (referred to hereafter as PTEC $E$-cad ${ }^{-1-}$ mice), E-cadherin expression was examined by indirect immunofluorescence and Western analysis (Figure 1) in primary cultures of PTECs and histological sections of control $\left(E-\right.$ cad $^{+/ f l o x} ;$ Sglt2.Cre $)$ and PTEC E-cad ${ }^{-1-}\left(E-\right.$ cad $^{- \text {flox }}$; Sglt2.Cre) mice. E-cadherin expression was not detected in PTECs and kidney proximal tubules (Figure 1A) of PTEC $E$-cad ${ }^{-1-}$ mice. Western blot analysis indicated a significant reduction $(>90 \%)$ of E-cadherin in PTECs isolated from PTEC E-cad ${ }^{-1-}$ mice (Figure 1, B and C).

\section{E-Cadherin Depletion in PTEC Up-Regulates Expression of Integrin $\alpha 3 \beta 1$}

Integrin $\alpha 3 \beta 1$ is a critical component of E-cadherinmediated cell-cell contact. ${ }^{15}$ To determine the effect of E-cadherin depletion on integrin $\alpha 3 \beta 1$, confocal microscopy, indirect immunofluorescence, and Western blot were performed. A stronger lateral membrane staining for integrin $\alpha 3$ and $\beta 1$ was shown clearly by XZ sections of their immunofluorescence staining in cultured $E$-cad ${ }^{-1-}$ PTECs compared with control PTECs (Figure 2A). $\alpha 3$ Integrin colocalized with E-cadherin in cultured PTECs of control mice (Figure 2A). The immunofluorescence staining demonstrated that depletion of E-cadherin up-regulated both $\alpha 3$ and $\beta 1$ integrin at the lateral membrane. This may serve to compensate for loss of E-cadherin to maintain cell-cell adhesion. Consistent with these immunofluorescence results, Western blot and real-time RT-PCR analysis demonstrated a significant increase of $\alpha 3$ and $\beta 1$ integrin protein and transcripts in $E$-cad ${ }^{-1-}$ PTECs compared with control
(Figure 2, B-E). To determine whether E-cadherin depletion caused the up-regulation of integrin $\alpha 3 \beta 1$, we forced the expression of E-cadherin (wild-type E-cad) in control and $E$ - $\mathrm{cad}^{-1-}$ PTECs. After transfection with wild-type Ecad, increased $\alpha 3$ and $\beta 1$ integrin protein levels in $E$-cad ${ }^{-1-}$ PTECs were reduced (Figure 2, F and G), and their protein levels in control PTECs were also reduced. This result confirmed that depletion of E-cadherin in PTECs caused the up-regulation of integrin $\alpha 3 \beta 1$ expression.

\section{Effect of E-Cadherin Depletion on $\beta$-Catenin, Z0-1, and} $\mathrm{N}$-Cadherin Levels in PTECs

To determine if loss of E-cadherin affects other adhesion molecules of cell-cell junctions, expression of $\beta$-catenin, ZO-1, and N-cadherin was examined by Western blot and immunofluorescence staining in cultured control and E-cad ${ }^{-1-}$ PTECs (Figure 3). Expression and localization of ZO-1, an epithelial tight junction molecule, were unaffected by loss of E-cadherin (Figure 3, A-C). N-cadherin is normally expressed by PTECs, ${ }^{29}$ and loss of E-cadherin is often accompanied by a cadherin switch to $\mathrm{N}$-cadherin during EMT. ${ }^{30}$ We found that $\mathrm{N}$-cadherin expression shown by both immunofluorescence staining (Figure 3A) and Western blot (Figure 3, B and C) was not affected by the loss of Ecadherin, and there was no cadherin switch. $\beta$-Catenin is the direct binding partner of E-cadherin intracellular domain anchoring E-cadherin to the actin cytoskeleton. Depletion of E-cadherin did not alter overall protein level of $\beta$-catenin (Figure 3, B and C); immunofluorescence showed a membrane staining pattern of $\beta$-catenin in cultured $E$-cad ${ }^{-1-}$ PTECs slightly different from strong membrane staining in control PTECs (Figure 3A).

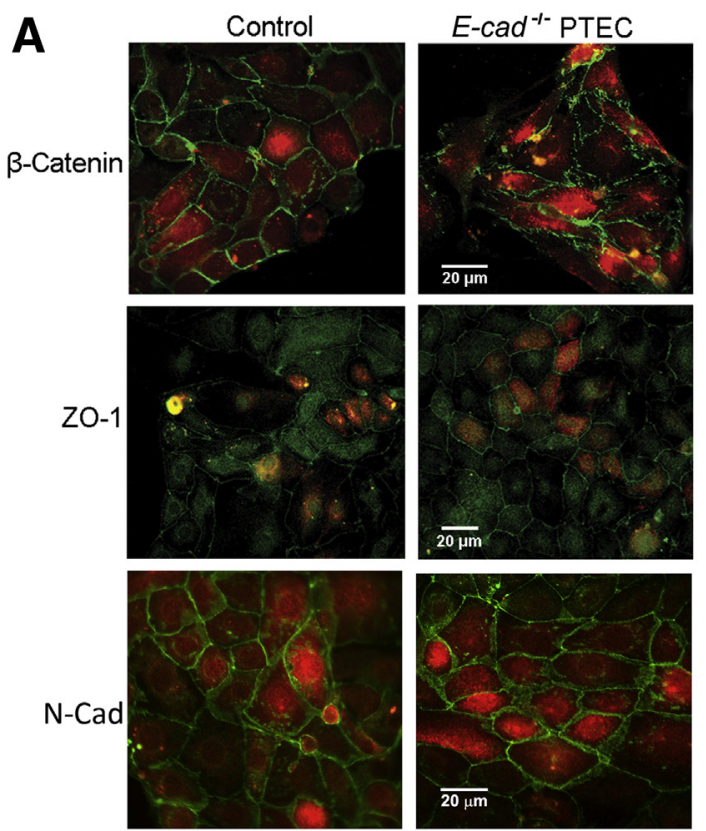

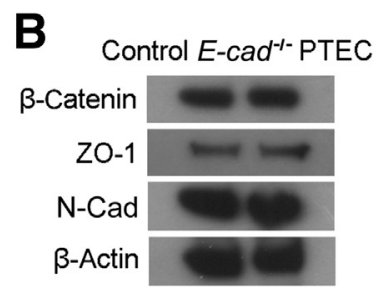

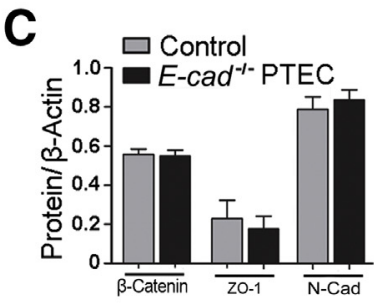

Figure 3 Effect of E-cadherin deletion on $\beta$-catenin, zonula occludens 1 (Z0-1), and $\mathrm{N}$-cadherin expression in proximal tubular epithelial cell (PTEC). A: Immunofluorescence staining of cultured control and $E$-cad ${ }^{-1-}$ PTEC stained for $\beta$-catenin (green), Z0-1 (green), N-cadherin (green), and PTEC marker megalin (red). B and $\mathbf{C}$ : Western blot analysis and quantification of $\beta$-catenin, Z0-1, and $\mathrm{N}$-cadherin ( $\mathrm{N}$-cad) in lysates of cultured control and $E$-cad ${ }^{-1-}$ PTEC. Data are shown as means \pm SD (C). $n=3$ (C). Scale bar $=20$ $\mu \mathrm{m}(\mathbf{A})$. 

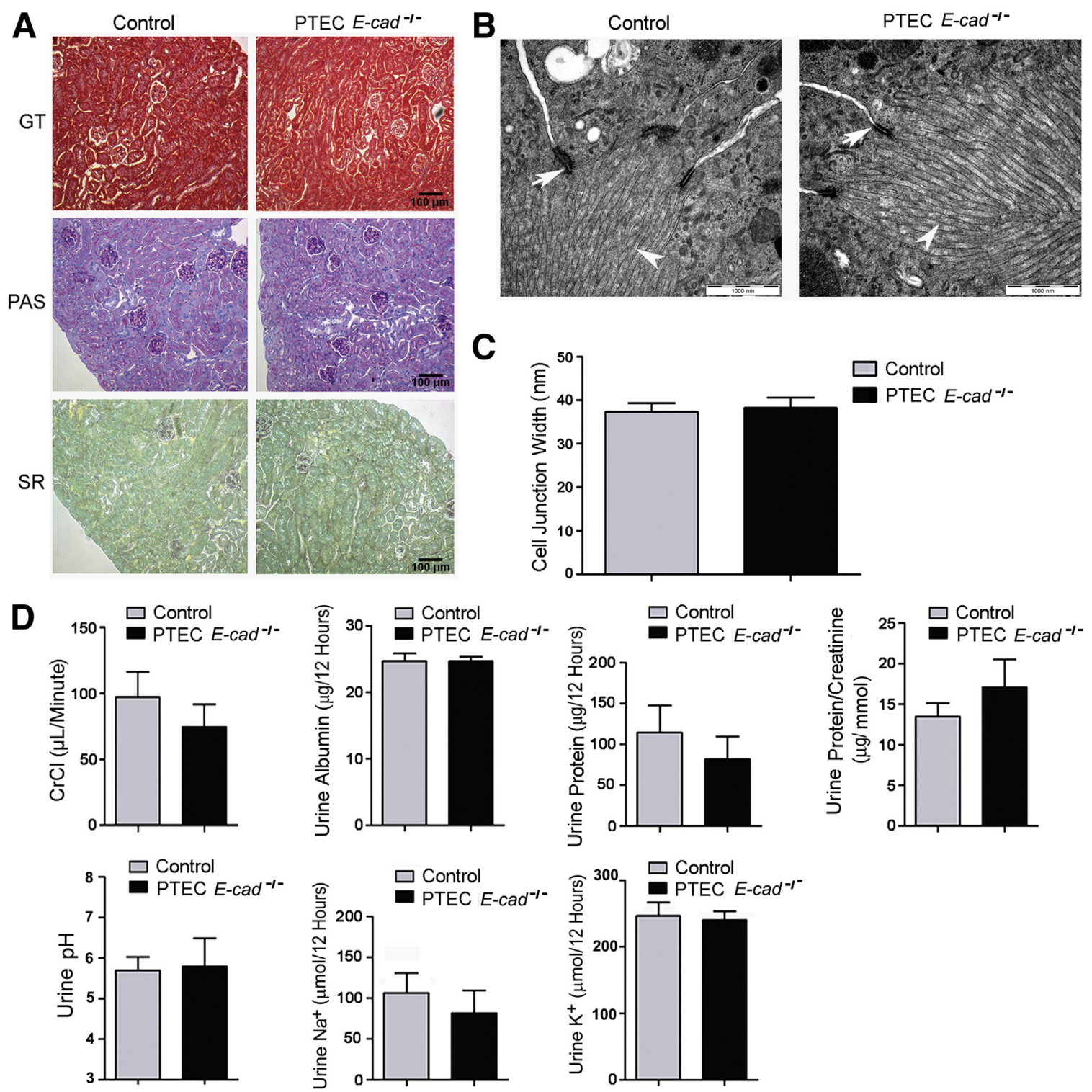

Figure 4 Deletion of E-cadherin does not have significant impact on the ultrastructure or morphology of proximal tubular epithelial cell (PTEC) and kidney function. A: Representative images of renal histology of control and PTEC $E$-cad ${ }^{-1-}$ mice aged 3 to 5 months. Gomori trichrome (GT), periodic acid Schiff (PAS), and Sirius Red staining (SR). B and C: Electron microscopic images and quantification of tight junction (arrows) width in kidney tissue of control and PTEC $E$ - $\mathrm{cad}^{-/-}$mice aged 3 to 5 months. D: Kidney function of control and PTEC $E$-cad ${ }^{-/-}$mice aged 3 to 5 months was determined by creatinine clearance (CrCl), urinary albumin and protein, urinary protein/creatinine, urine $\mathrm{pH}$, and urine $\mathrm{Na}^{+}$and $\mathrm{K}^{+}$excretion. Data are shown as means $\pm \mathrm{SD}(\mathbf{C}$ and $\mathbf{D})$. $n=3(\mathbf{C}$ and $\mathbf{D})$. Scale bars: $100 \mu \mathrm{m}(\mathbf{A}) ; 1000 \mathrm{~nm}$ (B).

\section{Depletion of E-Cadherin in PTECs Does Not Have Significant Impact on the Ultrastructure and Morphology of PTECs and Kidney Function in Vivo}

To examine the potential effects of E-cadherin depletion in PTECs on structure of proximal tubules and kidney histology, electron microscopy and histochemistry were performed. Electron microscopy, Gomori trichrome staining (extracellular matrix proteins), periodic acid-Schiff staining (basement membranes, glycoproteins), and Sirius Red staining (collagen) revealed no obvious changes in ultrastructure of kidney proximal tubules. The electron microscopy images showed no obvious difference in tight junctions and microvilli between the PTECs of E-cad ${ }^{-1-}$ and control mice (Figure 4B), suggesting that loss of PTEC polarity in $E-$ cad $^{-/-}$mice is unlikely. ${ }^{31,32}$ No changes were found in ECM staining of kidney between PTEC E-cad ${ }^{-1-}$ and control mice aged 3, 4, or 5 months (Figure 4, A and C). Urine and serum analysis was also performed to examine kidney function of PTEC $E$-cad ${ }^{-1-}$ mice (Figure 4D). No significant changes were observed in creatinine clearance, urinary albumin, total protein, $\mathrm{Na}^{+}$and $\mathrm{K}^{+}$excretion, urinary protein/creatinine ratio, and urine pHin PTEC $E$ - $\mathrm{cad}^{-/-}$mice compared with control mice aged 3, 4, or 5 months. Glucose was undetectable in urine samples collected from both PTEC $E$-cad ${ }^{-1-}$ and control mice. Thus, 

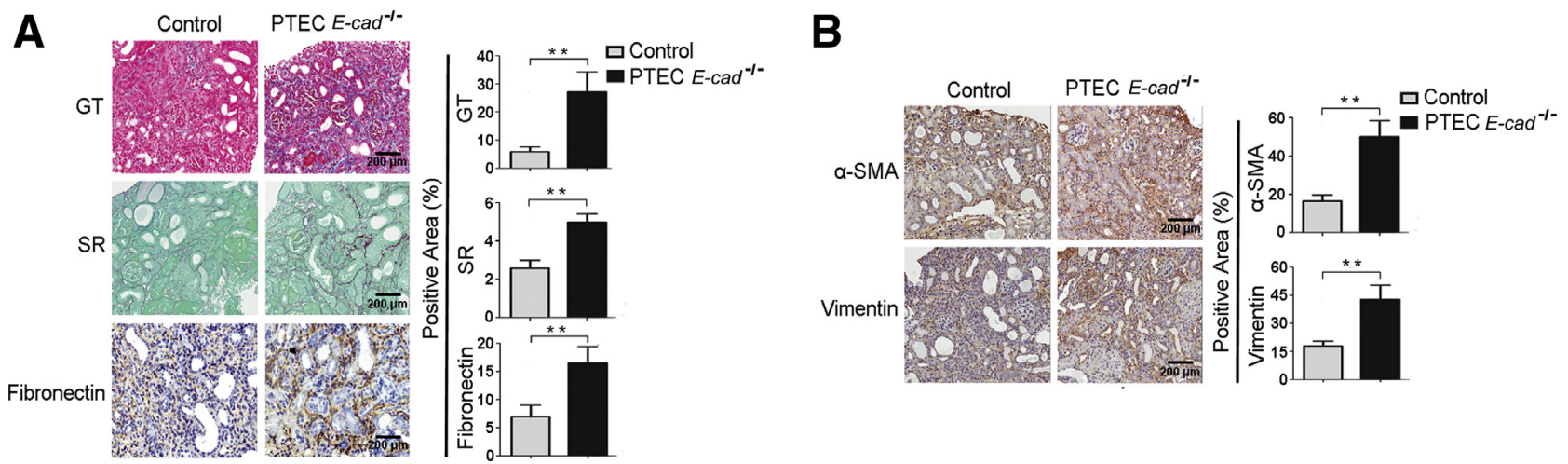

Figure 5 Deletion of E-cadherin in proximal tubular epithelial cell (PTEC) enhances unilateral ureteral obstruction (UU0)-induced kidney fibrosis. A: Kidney histology and immunohistochemical staining for Gomori trichrome (GT), Sirius Red (SR), and fibronectin expression of control and PTEC Ecad ${ }^{-/-}$mice after $^{-}$ UU0. Quantitation of the staining data. B: Immunohistochemical staining and quantification of $\alpha$-SMA and vimentin in kidney of control and PTEC E-cad ${ }^{-/-}$ mice after UU0. Data are shown as means \pm SD (A and B). $n=6(\mathbf{A}$ and $\mathbf{B}) .{ }^{* \star} P<0.01$. Scale bar $=200 \mu \mathrm{m}(\mathbf{A}$ and $\mathbf{B})$.

depletion of E-cadherin by itself did not significantly alter the structure of proximal tubules and the kidney functions examined. No fibrosis was observed after loss of E-cadherin in PTECs.

\section{Depletion of E-Cadherin in PTEC Enhances UU0-Induced Kidney Fibrosis}

Lack of structural and functional changes after PTEC deletion of E-cadherin in normal mice led us to investigate the effect of E-cadherin depletion on fibrosis, using a classic murine model of kidney fibrosis, UUO, which is characterized by selective up-regulation of TGF- $\beta 1$ and profibrotic changes in the PTEC. ${ }^{33,34}$ UUO was performed in PTEC - $_{\text {- }}{ }^{-1-}$ and control mice. We found that after UUO, kidney fibrosis was much more severe in PTEC $E$ - $c a d^{-1-}$ mice compared with that in littermate controls (Figure 5). Gomori trichrome staining and Sirius Red staining for extracellular matrix were significantly more intense in kidney cortex of PTEC $E$ - $\mathrm{cad}^{-1-}$ mice compared with those of control mice after UUO (Figure 5A). Immunohistochemical staining for fibronectin (Figure 5A), $\alpha$-SMA, and vimentin (Figure 5B) was also significantly more intense in kidney cortex of PTEC $E$-cad ${ }^{-1-}$ mice.

\section{Depletion of E-Cadherin in PTEC Enhances Integrin $\alpha 3-D e p e n d e n t$ TGF- $\beta 1-$ Induced Profibrotic Processes}

To address the mechanism underlying increased kidney fibrosis in PTEC $E$ - $\mathrm{cad}^{-1-}$ mice after UUO, we mimicked the in vivo environment of kidney fibrosis by treatment of primary cultures of PTECs from control and PTEC $E$ - $c a d^{-1-}$ mice with TGF- $\beta 1$, a key profibrotic cytokine ${ }^{35,36}$ up-regulated in PTECs after UUO. ${ }^{37}$ Immunofluorescence staining and Western blot analysis showed that the expression of both $\alpha$ SMA and vimentin was significantly increased after TGF- $\beta 1$ treatment in $E$-cad ${ }^{-1-}$ PTECs compared with control PTECs (Figure 6, A-D). Knock-down of integrin $\alpha 3$ using RNA interference (Supplemental Figure S3A) resulted in less
$\alpha$-SMA expression in TGF- $\beta 1-$ treated $E$-cad ${ }^{-1-}$ PTECs (Figure 6E). This result demonstrated that the increased $\alpha$-SMA expression of $E$-cad ${ }^{-/-}$PTECs depends on upregulation of integrin $\alpha 3$. However, silencing of integrin $\beta 1$ (Supplemental Figure S3B) failed to block the increase of $\alpha$-SMA expression (Figure 6F). Moreover, TGF- $\beta 1$ induction of $\alpha$-SMA in $E$-cad ${ }^{-1-}$ PTECs was further increased by $\beta 1$ integrin siRNA (Figure 6F). The contrasting results from selective knock-down of the two subunits of $\alpha 3 \beta 1$ integrin demonstrated a dependence on $\alpha 3$ but not $\beta 1$ integrin in TGF- $\beta 1$-induced profibrotic changes in $E$-cad ${ }^{-/-}$PTECs. Taken together, loss of E-cadherin in kidney PTECs increased TGF- $\beta 1$-induced profibrotic processes that were dependent on up-regulation of $\alpha 3$ integrin.

\section{ILK Mediates Integrin $\alpha 3$-Dependent Enhancement of TGF- $\beta 1$-Induced Profibrotic Processes in $\mathrm{Ecad}^{-/-}$ PTEC}

ILK and its downstream signaling have been reported to regulate TGF- $\beta 1$-induced profibrotic processes and fibrosis. ${ }^{20,22}$ Moreover, involvement of other major intracellular pathways (including Rho family GTPases, MEK, p38 kinase, c-Jun NH2-terminal kinase, PI3K, and PKC) has been excluded from $\alpha 3 \beta 1$ integrin signaling. ${ }^{38} \mathrm{We}$ therefore examined whether ILK and its downstream signaling are involved in the $\alpha 3$ integrin-dependent profibrotic changes after loss of E-cadherin. Western blot analysis (Figure 7A) showed that expression of ILK was higher in TGF- $\beta 1-$ treated $\mathrm{Ecad}^{-1-}$ PTECs than controls. By RT-PCR, the expression of Snail1, a key profibrotic transcription factor targeted by ILK through $\beta$-catenin, was also significantly increased in TGF- $\beta 1$-treated $E$-cad ${ }^{-1-}$ PTECs (Figure 7B). The increase of Snaill expression in $E$-cad ${ }^{-1-}$ PTECs was accompanied by an increase of TGF- $\beta 1-$ stimulated collagen I transcription, showing increased ECM production by $E$ - $\mathrm{cad}^{-1-}$ PTECs (Figure 7B). Given the evidence of $\alpha 3$ integrin-dependent 
A

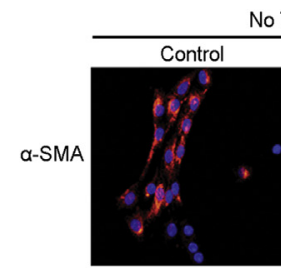

E-cad ${ }^{-1-}$ PTEC
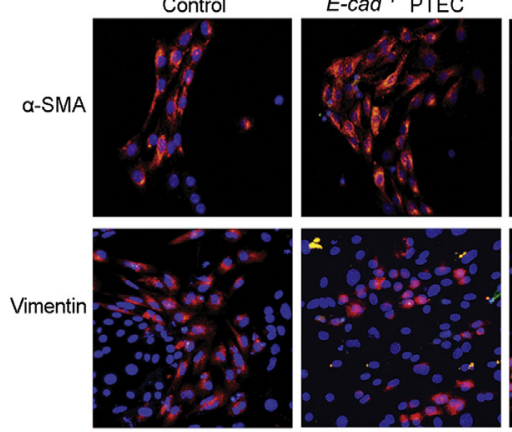

\section{C}

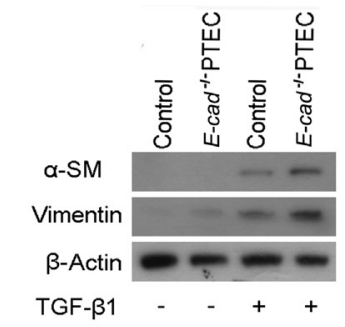

$\mathbf{E}$
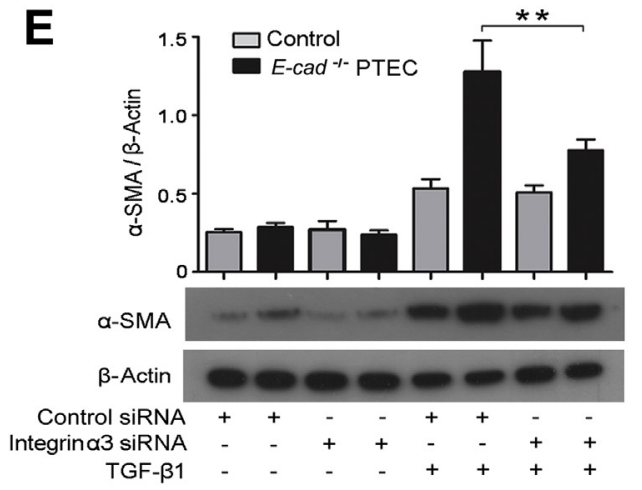
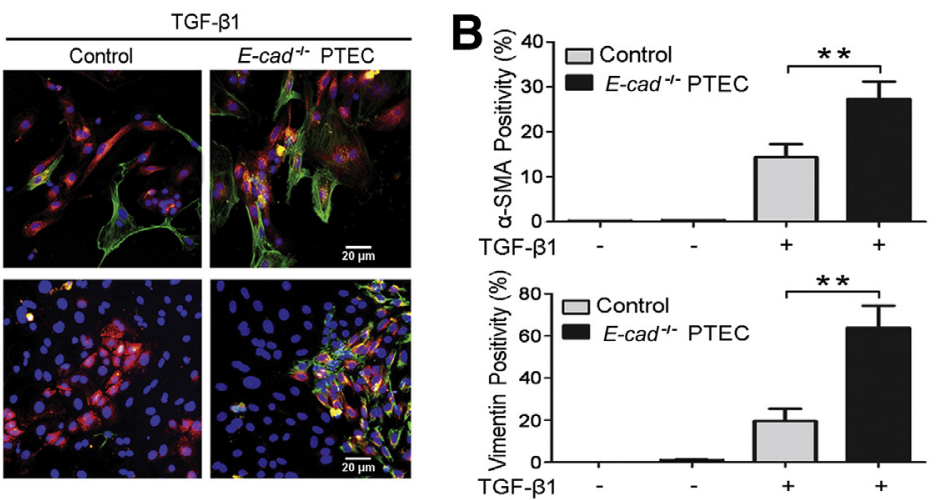

D

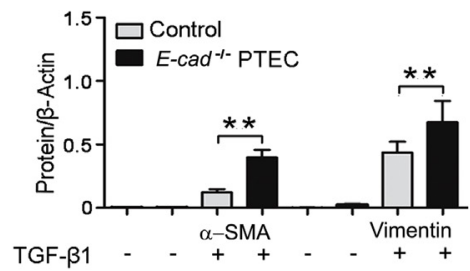

$\mathbf{F}$

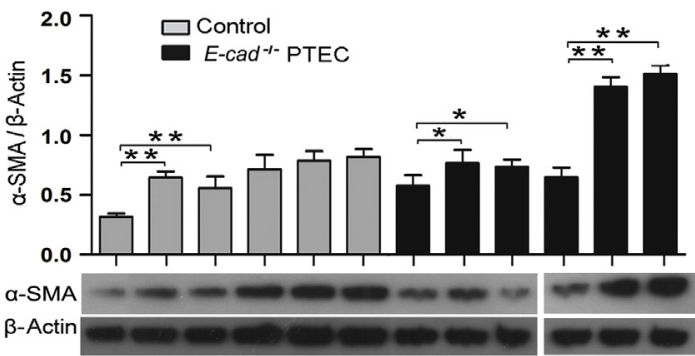

Control siRNA $60 \quad-\quad-60 \quad-\quad-60 \quad-\quad-60 \quad-\quad-$ Integrin $\beta 1$ siRNA $\quad-\quad 30 \quad 60 \quad-\quad 30 \quad 60 \quad-\quad 3060 \quad-\quad 30 \quad 60$ $(\mathrm{pmol} / \mathrm{mL})$

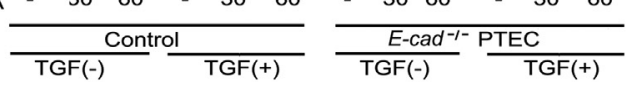

Figure 6 Deletion of E-cadherin in proximal tubular epithelial cell (PTEC) enhances integrin $\alpha 3$-dependent transforming growth factor (TGF)- $\beta 1-$ induced epithelial-mesenchymal transition. A and B: Immunofluorescence staining and quantification of $\alpha$-smooth muscle actin ( $\alpha$-SMA; green), vimentin (green), and PTEC marker megalin (red) in cultured control and $E$-cad ${ }^{-1-}$ PTEC, treated or not with $5 \mathrm{ng} / \mathrm{mL}$ TGF- $\beta 1$ for 48 hours. TGF- $\beta 1$ induces a significantly greater number of $\alpha$-SMA or vimentin staining cells in $E$-cad ${ }^{-1-}$ PTEC compared with control. C and D: Western blot analysis of $\alpha$-SMA and vimentin in lysates of cultured control and E-cad ${ }^{-/-}$PTEC, treated or not with $5 \mathrm{ng} / \mathrm{mL}$ TGF- $\beta 1$ for 48 hours. E: Western blot analysis and quantification of $\alpha$-SMA in lysates of cultured control and E-cad ${ }^{-1-}$ PTEC transiently transfected with $60 \mathrm{pmol} / \mathrm{mL}$ control or $60 \mathrm{pmol} / \mathrm{mL}$ integrin $\alpha 3$ siRNA, with or without $5 \mathrm{ng} / \mathrm{mL}$ TGF- $\beta 1$ treatment for 48 hours. Integrin $\alpha 3$ siRNA significantly reduces TGF- $\beta 1$-induced $\alpha$-SMA in $E$-cad ${ }^{-1-}$ PTEC. F: Western blot analysis and quantification of $\alpha$-SMA in lysates of cultured control and E-cad ${ }^{-1-}$ PTEC transiently transfected with $60 \mathrm{pmol} / \mathrm{mL}$ control or 30 or $60 \mathrm{pmol} / \mathrm{mL}$ integrin $\beta 1 \mathrm{siRNA}$, with or without $5 \mathrm{ng} /$ $\mathrm{mL}$ TGF- $\beta 1$ treatment for 48 hours. Integrin $\beta 1$ siRNA did not reduce but increased TGF- $\beta 1$-induced $\alpha$-SMA in $E$-cad ${ }^{-1-}$ PTEC. Data are shown as means \pm SD (B and $\mathbf{D}-\mathbf{F}) . n=4(\mathbf{B}) ; n=3(\mathbf{D}-\mathbf{F}) .{ }^{*} P<0.05,{ }^{* *} P<0.01$. Scale bar $=20 \mu \mathrm{m}(\mathbf{A}$ and $\mathbf{B})$.

increase of TGF- $\beta 1$-induced profibrotic processes in $E$ $\mathrm{cad}^{-1-}$ PTECs, we next tested whether $\alpha 3$ integrin mediates the profibrotic changes through up-regulation of ILK by siRNA knockdown of $\alpha 3$ and $\beta 1$ integrins. Silencing of $\alpha 3$ but not $\beta 1$ integrin significantly reduced TGF- $\beta 1-$ induced up-regulation of ILK in control and $E$-cad ${ }^{-/-}$PTECs (Figure 7C). To confirm a3 integrin-dependent upregulation of ILK is responsible for the enhanced TGF$\beta 1$-induced profibrotic processes in $E$-cad ${ }^{-1-}$ PTECs, we performed siRNA silencing of ILK to control and $E$-cad ${ }^{-1-}$ PTECs (Supplemental Figure S3C). TGF- $\beta 1$-induced $\alpha$-SMA protein expression in $E$-cad ${ }^{-/-}$PTECs was significantly higher than in control PTECs, and ILK siRNA reduced the $\alpha$-SMA protein in $E$-cad ${ }^{-1-}$ PTECs to the level of control PTECs (Figure 7D), proving that the enhancement of TGF- $\beta 1$-induced profibrotic processes in $E$-cad ${ }^{-/-}$ PTECs is ILK dependent.

Src Phosphorylation of $\beta$-Catenin and $p$ - $\beta$-CateninY654/Smad2 Transcriptional Complex Mediates a3-Integrin-Dependent Up-Regulation of ILK

To explore an $\alpha 3$ but not $\beta 1$ integrin-dependent upregulation of ILK, we examined Src kinase activity, which 
A

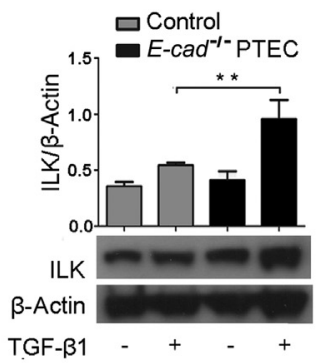

C

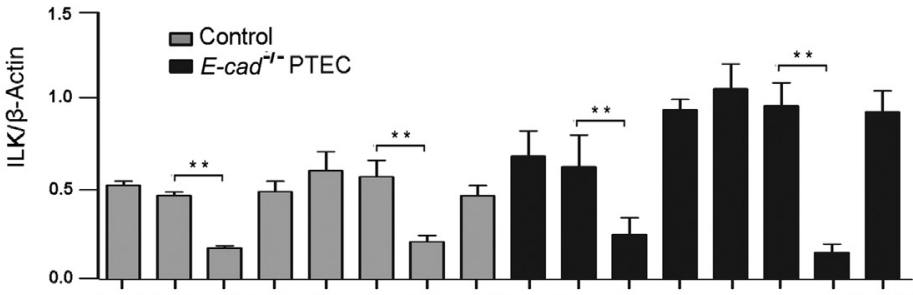

ILK

$\beta$-Actin

TGF-B1 -

Control siRNA Integrin $\alpha 3$ siRNA Integrinß1siRNA -

B

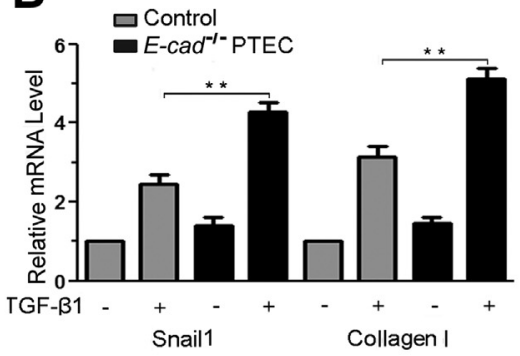

D

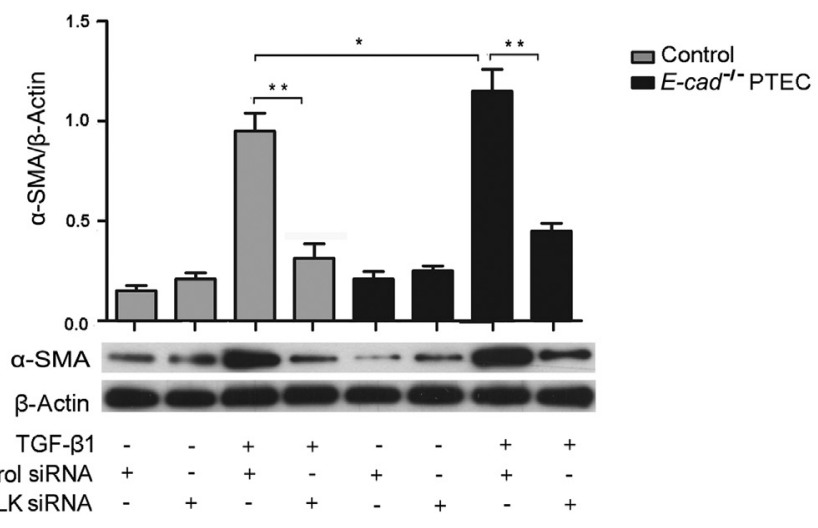

Figure 7 ILK mediates integrin $\alpha 3$-dependent enhancement of transforming growth factor (TGF)- $\beta 1$-induced profibrotic processes in $\mathrm{Ecad}^{-/-}$proximal tubular epithelial cell (PTEC). A: Western blot analysis and quantification of ILK in lysates of cultured control and E-cad ${ }^{-/-}$PTEC, treated or not with $5 \mathrm{ng} / \mathrm{mL}$ TGF- $\beta 1$ for 48 hours. TGF- $\beta 1$ treatment induces significantly higher levels of ILK protein in $E$-cad ${ }^{-1-}$ PTEC compared with control. B: Real-time RT-PCR analysis of Snail 1 and collagen I expression in cultured control and $\mathrm{Ecad}^{-1-}$ PTEC, treated or not with $5 \mathrm{ng} / \mathrm{mL}$ TGF- $\beta 1$ for 48 hours. TGF- $\beta 1-$ induced increases of both Snail1 and collagen I mRNA levels are significantly higher in E-cad ${ }^{-1-}$ PTEC compared with control. C: Western blot analysis and quantification of ILK in lysates of cultured control and E-cad ${ }^{-1-}$ PTEC, transfected with integrin $\alpha 3$ or $\beta 1$, or $60 \mathrm{pmol} / \mathrm{mL}$ control siRNA with or without TGF- $\beta 1$ treatment for 24 hours. Integrin $\alpha 3$ but not $\beta 1$ siRNA significantly reduces TGF- $\beta 1$-induced ILK in both control and E-cad ${ }^{-1-}$ PTEC. D: Western blot analysis and quantification of $\alpha$-SMA in lysates of cultured control and $E$-cad ${ }^{-1-}$ PTEC, transfected with ILK, or $60 \mathrm{pmol} / \mathrm{mL}$ control siRNA with or without TGF- $\beta 1$ treatment. Data are shown as means \pm SD (A-D). $n=3(\mathbf{A}-\mathbf{D}) .{ }^{*} P<0.05,{ }^{*}{ }^{*} P<0.01$. was reported downstream of $\alpha 3$ integrin independent of $\alpha 3 \beta 1$-mediated cell-matrix adhesion. ${ }^{38}$ Interestingly, TGF- $\beta 1$-induced activation of Src (p-Src) was significantly higher in $E$ - $\mathrm{cad}^{-1-}$ PTECs compared with control PTECs (Figure 8A). Src kinase is known for its dissociation of $\beta$-catenin from E-cadherin-mediated cell-cell adhesion by phosphorylation of $\beta$-catenin at $\mathrm{Y}-654$, whereas a TGF- $\beta$ recepter $1 /$ E-cadherin $/ \alpha 3 \beta 1$ integrin-dependent $p-\beta$ catenin-Y654/p-Smad2 complex was induced by TGF- $\beta 1{ }^{7}$ This prompted us to examine whether the $\alpha 3$ integrindependent activation of Src kinase underlies the $\mathrm{p}-\beta$ catenin-Y654/Smad2 complex induction in absence of E-cadherin. Indeed, we found by coimmunoprecipitation assay that $\mathrm{p}-\beta$-catenin-Y654/p-Smad2 complex formation was significantly higher in TGF- $\beta 1-$ treated $E$-cad ${ }^{-1-}$ PTECs compared with control PTECs (Figure 8B). Given that $\alpha 3$ integrin-dependent up-regulation of ILK is responsible for the EMT of E-cad ${ }^{-l-}$ PTECs, we further examined whether p- $\beta$-catenin-Y654/p-Smad2 complex regulates a transcriptional activation of ILK. Sequence analysis by online software Transcriptional Regulatory Element Database (https://cb.utdallas.edu/cgi-bin/TRED/ tred.cgi?process $=$ home; last accessed February 15, 2016) revealed a Smad binding sequence (GTCT) located at 247 to 250 of mouse ILK promoter (Figure 8C). Chromatin immunoprecipitation showed an increase of $\mathrm{p}-\mathrm{Smad} 2$ binding at 247 when complexed with $\mathrm{p}$ - $\beta$-catenin-Y654 (Figure $8 \mathrm{C}$ ). Thus, our results delineated a novel $\alpha 3$ but not $\beta 1$ integrin-dependent and $\mathrm{p}-\beta$-catenin-Y654/pSmad2-mediated up-regulation of ILK in $E$ - $\mathrm{cad}^{-1-}$ PTECs.

\section{Knockout of E-Cadherin in PTEC Aggravates Kidney} Fibrosis in UUO and IR via $\alpha 3$ Integrin/ILK

To further examine the aggravation of kidney fibrosis after UUO in PTEC $E$ - $\mathrm{Cad}^{-1-}$ mice, we investigated the activity of 

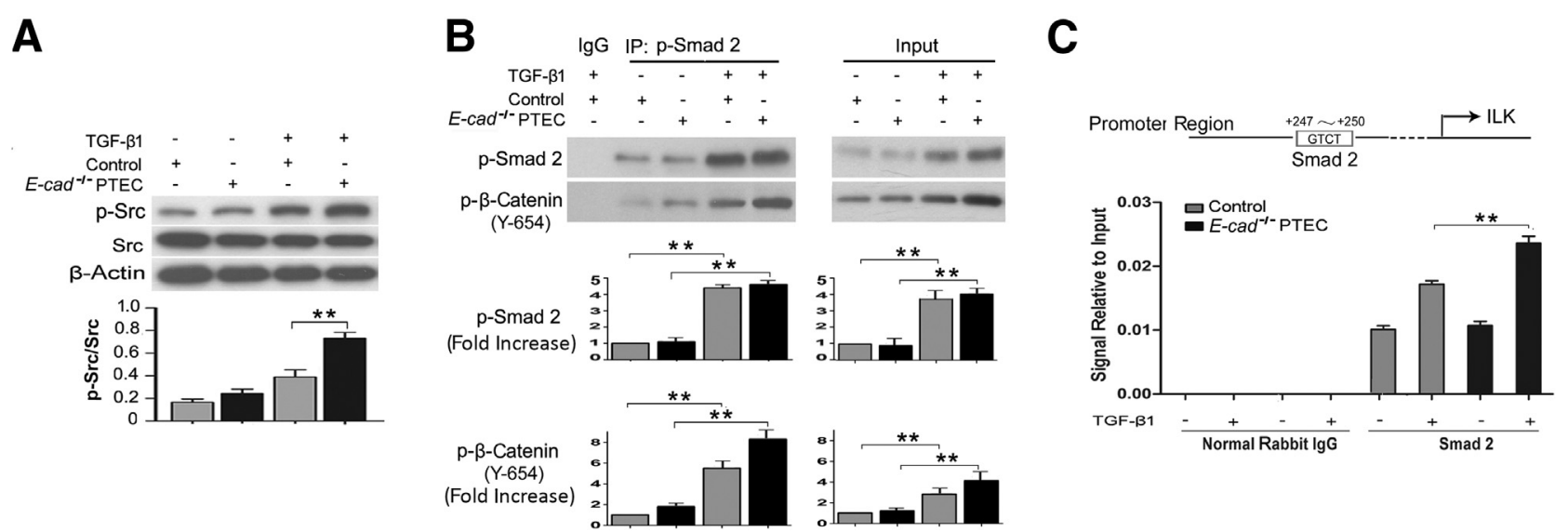

Figure 8 Src phosphorylation of $\beta$-catenin and $p$ - $\beta$-catenin-Y654/Smad 2 transcriptional complex mediates $\alpha 3$-integrin-dependent up-regulation of ILK. A: Western blot analysis and quantification of Src kinase in lysates of cultured control and E-cad ${ }^{-1-}$ proximal tubular epithelial cell (PTEC), treated or not with 5 $\mathrm{ng} / \mathrm{mL}$ transforming growth factor (TGF)- $\beta 1$ for 48 hours. TGF- $\beta 1$ treatment significantly activates Src kinase in E-cad ${ }^{-1-}$ PTEC compared with control. B: Coimmunoprecipitation (IP) of $\mathrm{p}-\beta$-catenin (Y-654) and P-Smad2 antibody from control and E-cad ${ }^{-1-}$ PTEC nuclear proteins with rabbit anti-P-Smad2 antibody. Purified rabbit IgG was used as a negative control. Immunoprecipitates were analyzed by Western blotting with anti-p- $\beta$-catenin ( $\mathrm{Y}-654)$ and anti-PSmad2 antibodies. Input refers to analysis of nuclear proteins before immunoprecipitation. Quantification of immunoblots (relative intensity) is shown by foldincrease in densitometry intensity (the intensity of the control is arbitrarily defined as 1 ). TGF- $\beta 1$ treatment induces significant activation of Smad2 in both control and $E$-cad ${ }^{-/}$PTEC nuclear proteins, whereas the phosphorylated $\beta$-catenin, $\mathrm{p}$ - $\beta$-catenin (Y-654) binding to Smad2 is significantly increased in $E$-cad ${ }^{-/-}$ PTEC compared to control. C: Chromatin immunoprecipitation (ChIP) assay of Smad2 binding site at position 247 of the mouse ILK promoter by amplification of 219 to 289 promoter region precipitated by rabbit anti-P-Smad2 antibody. Purified rabbit IgG was used as a negative control. Binding of Smad2 to ILK promoter at position 247 significantly increases in $E$-cad ${ }^{-/}$PTEC compared with control. Data are shown as means \pm SD $(\mathbf{A}-\mathbf{C}) . n=3(\mathbf{A}-\mathbf{C}) .{ }^{* *} P<0.01$.

ILK and consequent $\beta$-catenin nuclear translocation ${ }^{20,21}$ in kidney of control and PTEC E-cad ${ }^{-/-}$mice after UUO. PTEC-specific depletion of E-cadherin caused significant increases in ILK expression (Figure 9A) and nuclear accumulation of $\beta$-catenin in PTEC of PTEC $E$-cad ${ }^{-1-}$ mice (Figure 9B) after UUO. Inflammation is known to be an important contributor to fibrosis, including that arising through proximal tubular epithelial cells in UUO kidney. ${ }^{34}$ We next examined interstitial macrophage infiltration by immunohistochemical staining. There was no significant difference in the extent of macrophage infiltrations in UUO kidney of PTEC E-cad ${ }^{-1-}$ and control mice (Figure 9C). These results suggest that depletion of PTEC E-cadherin per se does not cause more inflammation, which could otherwise explain the increased kidney fibrosis of PTEC $E$ - $\mathrm{cad}^{-/-}$mice after UUO. However, there was a significant increase of $\alpha$-SMA expression in the proximal tubules and interstitial cells that, in some cases, overlapped with Cre expression in the PTEC E-cad ${ }^{-/-}$mice (Figure 9D). This proximal tubular specific Cre expression served as genetic labeling analogous to that of lineage-tagged mice. Presence of $\alpha$-SMA and Cre double staining provides in vivo evidence for profibrotic changes of PTEC. Profibrotic processes in E-cadherin depleted PTEC are therefore associated with increased ILK activity and nuclear accumulation of $\beta$-catenin in PTEC $E-$ cad $^{-1-}$ mice. In addition, the effect of PTEC E-cadherin depletion on kidney fibrosis was also examined in kidney IR model. The kidney fibrosis was much more severe in PTEC $E$-cad ${ }^{-1-}$ mice than control mice, as shown by Gomori trichrome and Sirius Red staining in kidney cortex 3 weeks after IR (Supplemental Figure S4A). $\alpha$-SMA expression was also significantly higher in PTEC of PTEC E-cad ${ }^{-1-}$ mice compared with that of control mice (Supplemental Figure S4B). Consistent with this, ILK expression was higher in IR kidney of PTEC E-cad ${ }^{-1-}$ mice (Supplemental Figure S4C). Taken together, our results demonstrate that up-regulation of ILK and consequent profibrotic genes in E-cadherin-deficient PTEC contributed to the increase of kidney fibrosis in PTEC $E$-cad ${ }^{-1-}$ mice after UUO or IR.

\section{Discussion}

In this study, we show for the first time, by conditional depletion of E-cadherin from mouse proximal tubular epithelial cells, that E-cadherin in kidney protects against fibrosis. Ablation of E-cadherin from proximal tubular epithelial cells up-regulated $\alpha 3 \beta 1$ integrin, but did not result in a significant alteration of kidney structure or function in otherwise normal mice. However, after UUO, absence of E-cadherin in murine kidney worsened fibrosis through promotion of profibrotic processes by an $\alpha 3$ integrin - and ILK-linked mechanism. Our study provides in vivo evidence for a protective role of E-cadherin against fibrosis, and reveals a novel $\alpha 3$ integrin $/ \mathrm{p}-\beta$-catenin-Y654/ p-Smad2-mediated up-regulation of ILK in promotion of TGF- $\beta$-induced profibrotic changes on loss of E-cadherin.

Cross talk between integrins and cadherins has been investigated in integrin-mediated cell-matrix interaction and E-cadherin-mediated cell-cell adhesion. ${ }^{14,39,40}$ Upregulation of adherens junction-associated $\alpha 3 \beta 1$ integrin on loss of E-cadherin has not been identified previously. Coincidently, both elevated $\alpha 3 \beta 1$ integrin levels and loss of Ecadherin have each separately been associated with 

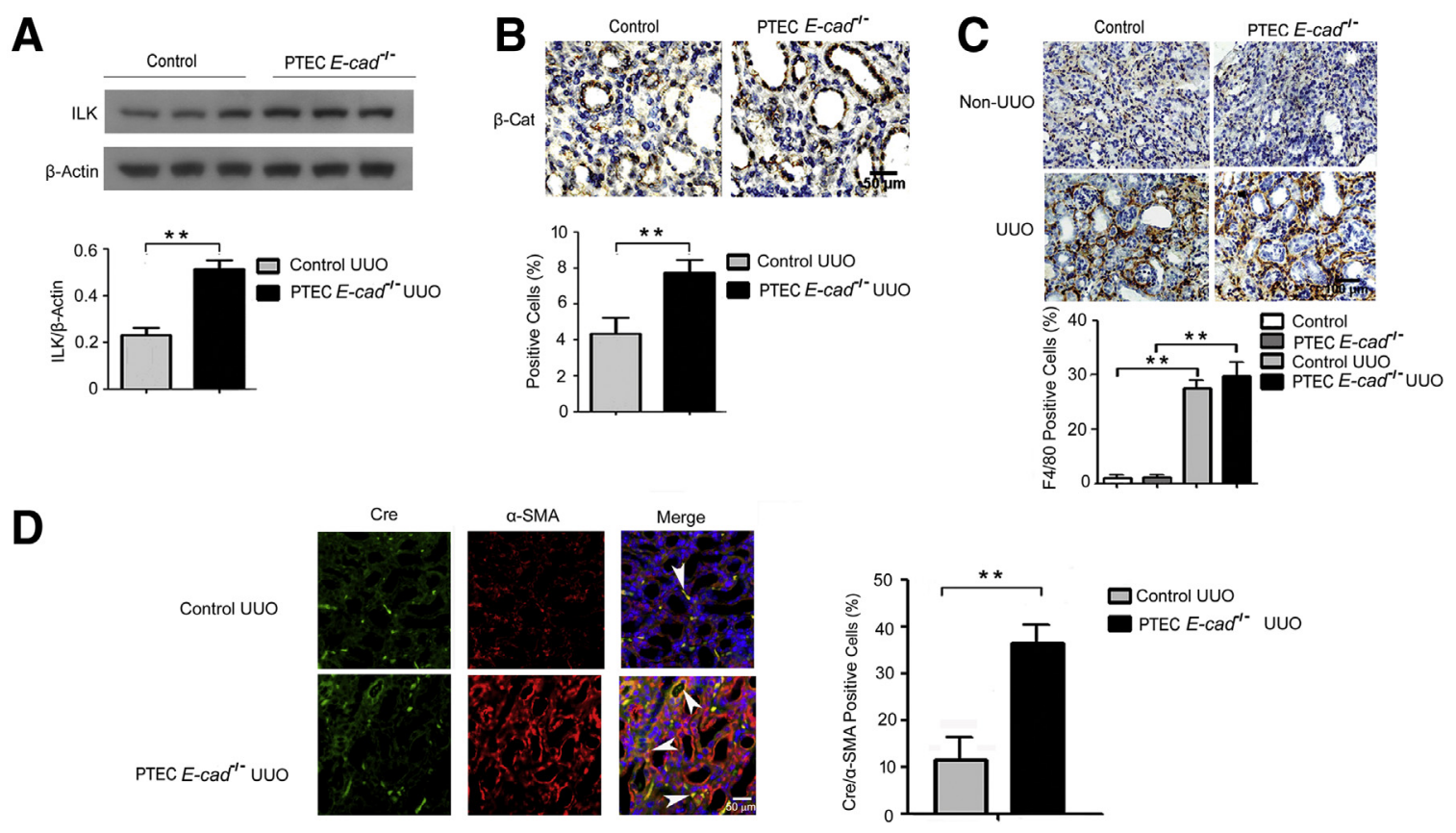

Figure 9 Deletion of E-cadherin in proximal tubular epithelial cell (PTEC) aggravates kidney fibrosis in unilateral ureteral obstruction (UU0) through upregulation of epithelial-mesenchymal transition (EMT). A: Western blot analysis and quantification of ILK. B: Immunohistochemical staining and quantification of $\beta$-catenin nuclear translocation in kidney of control and PTEC E-cad ${ }^{-1-}$ mice after UUO. ILK protein levels are significantly higher in UUO kidney of PTEC

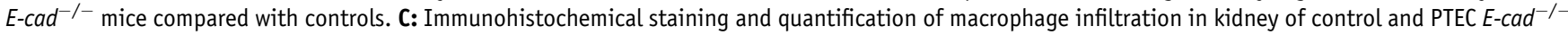
mice with or without UU0. Compared with non-UUO (contralateral kidneys). D: Immunofluorescence staining of Cre (green) and $\alpha$-SMA (red) and merged double positive proximal tubular cells (arrowheads) in kidney of control and PTEC E-cad ${ }^{-1-}$ mice after UUO. Significantly higher numbers of $\alpha$-SMA and Cre double-positive proximal tubule cells are seen in UUO kidney of PTEC E-cad ${ }^{-1-}$ mice compared with controls. Data are shown as means \pm SD (B-D). $n=6$ (B-D). ${ }^{* * P}<0.01$. Scale bars: $50 \mu \mathrm{m}$ (B and D); $100 \mu \mathrm{m}$ (C).

invasiveness of malignant carcinomas, mimicking our findings in PTEC. ${ }^{41,42}$ Herein, we provide the first evidence linking loss of E-cadherin with up-regulation of $\alpha 3 \beta 1$ integrin within cell-cell adhesion compartment in noncancerous epithelial cells.

$\alpha 3 \beta 1$ Integrin has been found to enhance E-cadherindependent cell-cell adhesion via interaction with CD151 ${ }^{15}$ or to down-regulate E-cadherin by binding to uPAR. ${ }^{38}$ Kim et $\mathrm{al}^{7,18}$ demonstrated that mice with specific depletion of lung epithelial $\alpha 3$ integrin failed to develop lung fibrosis. However, the underlying mechanism revealed was that $\alpha 3$ integrin binding to E-cadherin was required for $\alpha 3 \beta 1$ integrin-E-cadherin-TGF- $\beta \mathrm{R} 1$ cocluster formation at epithelial cell surface, leading to phosphorylation of E-cadherin bond $\beta$-catenin (pY654- $\beta$-catenin) and thereby p-Smad2-pY654- $\beta$-catenin complexes formation to initiate profibrotic processes. ${ }^{7}$ The $\alpha 3$ integrin-dependent signaling uncovered by our E-cadherin depletion study rules out a requirement of E-cadherin for $\alpha 3 \beta 1$ integrin-E-cadherinTGF- $\beta R 1$ cocluster-dependent epithelial profibrotic changes. Indeed, Kim et $\mathrm{al}^{7}$ also found that E-cadherin was present in TGF- $\beta$ R1 immunoprecipitates regardless of whether E-cadherin associates with the integrin (wild-type $\alpha 3$ integrin) or not (mutant $\alpha 3$ integrin). In addition, clusters of E-cadherin and TGF- $\beta R 1$ disappeared from the surface of $\alpha 3$ wild-type cells undergoing TGF- $\beta 1-$ induced EMT, but persisted on cells expressing mutant $\alpha 3$ integrin not responsive to TGF- $\beta 1$ stimulation. Interestingly, both studies from Kim et $\mathrm{al}^{7,18}$ and us identified p-Smad2pY654- $\beta$-catenin complex in mediating TGF- $\beta 1$-induced profibrotic changes. Our study revealed, for the first time, that ILK is the downstream target by p-Smad2-pY654- $\beta$ catenin complex.

ILK is induced by TGF- $\beta$ during EMT, whereas elevated ILK expression is known to contribute to EMT and fibrosis. ${ }^{20,43,44}$ However, TGF- $\beta$ signaling in upregulation of ILK remains largely unknown. We provided an $\alpha 3$ integrin-dependent mechanism for TGF- $\beta$ induction of ILK expression via p-Smad2-pY654- $\beta$ catenin, thereby linking $\alpha 3$ integrin to up-regulation of ILK rather than the conventional ILK activation through $\beta$ integrin in cell-matrix interaction. ${ }^{45}$ By using mutant $\alpha 3$ integrin with mutation outside its cell matrix binding domain, $\alpha 3$ integrin binding to nonmatrix ligands has been crucial in TGF- $\beta$-induced profibrotic changes. ${ }^{38} \mathrm{~A}$ Src activation followed by Slug expression underlies the $\alpha 3$ integrin-dependent profibrotic changes. ${ }^{38}$ However, a link between Src and up-regulation of Slug is missing, for Src is known to disrupt E-cadherin distribution rather than down-regulate E-cadherin. Our result showed that Srcdependent phosphorylation of $\beta$-catenin at Y654, known for Src disruption of E-cadherin distribution, led to $p$ Smad2-pY654- $\beta$-catenin complex formation and the complex-mediated transcription of ILK. Then, the Src 
activity is now logically associated with up-regulation of ILK, which up-regulates Slug. ${ }^{46}$ This cell-matrixindependent pathway within cell-cell adhesion compartment, as we found in current study, is less likely to involve conventional $\beta 1$ integrin/ILK or $\beta 1$ integrin/Src found in cell-matrix interaction. We speculate that the conventional $\beta 1$ integrin/ILK signaling in cell-matrix interaction is most likely physiological; podocyte-specific deletion of ILK led to loss of podocyte structure and function. ${ }^{47}$ It is the overexpression of ILK that causes profibrotic changes of tubular epithelial cells and kidney fibrosis. ${ }^{20,21}$ We therefore identify a central role for the $\alpha 3$ (rather than $\beta 1$ ) subunit of $\alpha 3 \beta 1$ integrin in TGF- $\beta-$ induced profibrotic processes on loss of E-cadherin.

Controversy exists as to whether tubular EMT is a contributor to kidney fibrosis. ${ }^{48,49}$ In our study, targeted deletion of E-cadherin from PTECs provided evidence for contribution of PTEC profibrotic processes to kidney fibrosis, analogous to data from studies using epithelial lineage-tagged mice. E-cadherin depletion in PTECs did not result in a secondary increase in interstitial macrophage infiltration. Endothelial-mesenchymal transition ${ }^{50,51}$ is also a most unlikely explanation in this case where E-cadherin depletion was restricted to tubular cells. We demonstrated that increased profibrotic processes in proximal tubules of PTEC $E$ - $\mathrm{Cad}^{-/-}$mice underlie the exacerbation of kidney fibrosis after UUO.

In conclusion, the current study provides in vivo evidence for the role of E-cadherin in kidney fibrosis, using conditional deletion of E-cadherin in proximal tubular cells. Our results suggest that E-cadherin's role in signal transduction associated with cell-cell adhesion is more dominant than its role in maintenance of adherens junction integrity in terminally differentiated adult tissues, such as kidney proximal tubules. The role of E-cadherin in suppressing $\alpha 3$ integrin/ILK and the definition of specific mechanisms leading to TGF- $\beta$-driven fibrosis may provide therapeutic targets for preventing kidney fibrosis and suggest therapeutic avenues in other organs where fibrosis leads to organ failure.

\section{Supplemental Data}

Supplemental material for this article can be found at http://dx.doi.org/10.1016/j.ajpath.2016.03.015.

\section{References}

1. Eddy AA: Molecular basis of renal fibrosis. Pediatr Nephrol 2000, 15: 290-301

2. Masszi A, Fan L, Rosivall L, McCulloch CA, Rotstein OD, Mucsi I, Kapus A: Integrity of cell-cell contacts is a critical regulator of TGFbeta 1-induced epithelial-to-myofibroblast transition: role for betacatenin. Am J Pathol 2004, 165:1955-1967

3. Orsulic S, Huber O, Aberle H, Arnold S, Kemler R: E-cadherin binding prevents beta-catenin nuclear localization and beta-catenin/LEF-1mediated transactivation. J Cell Sci 1999, 112(Pt 8):1237-1245
4. Zheng G, Lyons JG, Tan TK, Wang Y, Hsu TT, Min D, Succar L, Rangan GK, Hu M, Henderson BR, Alexander SI, Harris DC: Disruption of E-cadherin by matrix metalloproteinase directly mediates epithelial-mesenchymal transition downstream of transforming growth factor-betal in renal tubular epithelial cells. Am J Pathol 2009, 175:580-591

5. Kim MK, Maeng YI, Sung WJ, Oh HK, Park JB, Yoon GS, Cho CH, Park KK: The differential expression of TGF-beta1, ILK and wnt signaling inducing epithelial to mesenchymal transition in human renal fibrogenesis: an immunohistochemical study. Int J Clin Exp Pathol 2013, 6:1747-1758

6. Lovisa S, LeBleu VS, Tampe B, Sugimoto H, Vadnagara K, Carstens JL, Wu CC, Hagos Y, Burckhardt BC, Pentcheva-Hoang T, Nischal H, Allison JP, Zeisberg M, Kalluri R: Epithelial-to-mesenchymal transition induces cell cycle arrest and parenchymal damage in renal fibrosis. Nat Med 2015, 21:998-1009

7. Kim Y, Kugler MC, Wei Y, Kim KK, Li X, Brumwell AN, Chapman HA: Integrin alpha3beta1-dependent beta-catenin phosphorylation links epithelial Smad signaling to cell contacts. J Cell Biol 2009, 184:309-322

8. Grande MT, Sanchez-Laorden B, Lopez-Blau C, De Frutos CA, Boutet A, Arevalo M, Rowe RG, Weiss SJ, Lopez-Novoa JM, Nieto MA: Snaill-induced partial epithelial-to-mesenchymal transition drives renal fibrosis in mice and can be targeted to reverse established disease. Nat Med 2015, 21:989-997

9. Behrens J: Cadherins and catenins: role in signal transduction and tumor progression. Cancer Metastasis Rev 1999, 18:15-30

10. Gumbiner B, Stevenson B, Grimaldi A: The role of the cell adhesion molecule uvomorulin in the formation and maintenance of the epithelial junctional complex. J Cell Biol 1988, 107: $1575-1587$

11. Shapiro L, Weis WI: Structure and biochemistry of cadherins and catenins. Cold Spring Harb Perspect Biol 2009, 1:a003053

12. Perez-Moreno M, Fuchs E: Catenins: keeping cells from getting their signals crossed. Dev Cell 2006, 11:601-612

13. Kreidberg JA: Functions of alpha3betal integrin. Curr Opin Cell Biol 2000, 12:548-553

14. Martinez-Rico C, Pincet F, Thiery JP, Dufour S: Integrins stimulate E-cadherin-mediated intercellular adhesion by regulating Src-kinase activation and actomyosin contractility. J Cell Sci 2010, 123: $712-722$

15. Chattopadhyay N, Wang Z, Ashman LK, Brady-Kalnay SM, Kreidberg JA: alpha3beta1 Integrin-CD151, a component of the cadherin-catenin complex, regulates PTPmu expression and cell-cell adhesion. J Cell Biol 2003, 163:1351-1362

16. Bhowmick NA, Zent R, Ghiassi M, McDonnell M, Moses HL: Integrin beta 1 signaling is necessary for transforming growth factorbeta activation of p38MAPK and epithelial plasticity. J Biol Chem 2001, 276:46707-46713

17. Giancotti FG, Ruoslahti E: Integrin signaling. Science 1999, 285: $1028-1032$

18. Kim KK, Wei Y, Szekeres C, Kugler MC, Wolters PJ, Hill ML, Frank JA, Brumwell AN, Wheeler SE, Kreidberg JA, Chapman HA: Epithelial cell alpha3betal integrin links beta-catenin and Smad signaling to promote myofibroblast formation and pulmonary fibrosis. J Clin Invest 2009, 119:213-224

19. Borok Z: Role for alpha3 integrin in EMT and pulmonary fibrosis. J Clin Invest 2009, 119:7-10

20. Li Y, Tan X, Dai C, Stolz DB, Wang D, Liu Y: Inhibition of integrinlinked kinase attenuates renal interstitial fibrosis. J Am Soc Nephrol 2009, 20:1907-1918

21. Li Y, Yang J, Dai C, Wu C, Liu Y: Role for integrin-linked kinase in mediating tubular epithelial to mesenchymal transition and renal interstitial fibrogenesis. J Clin Invest 2003, 112:503-516

22. Shafiei MS, Rockey DC: The function of integrin-linked kinase in normal and activated stellate cells: implications for fibrogenesis in wound healing. Lab Invest 2012, 92:305-316 
23. Gu H, Marth JD, Orban PC, Mossmann H, Rajewsky K: Deletion of a DNA polymerase beta gene segment in T cells using cell type-specific gene targeting. Science 1994, 265:103-106

24. Tunggal JA, Helfrich I, Schmitz A, Schwarz H, Gunzel D, Fromm M, Kemler R, Krieg T, Niessen CM: E-cadherin is essential for in vivo epidermal barrier function by regulating tight junctions. Embo J 2005 , 24:1146-1156

25. Rubera I, Poujeol C, Bertin G, Hasseine L, Counillon L, Poujeol P, Tauc M: Specific Cre/Lox recombination in the mouse proximal tubule. J Am Soc Nephrol 2004, 15:2050-2056

26. Moriyama T, Kawada N, Ando A, Yamauchi A, Horio M, Nagata K, Imai E, Hori M: Up-regulation of HSP47 in the mouse kidneys with unilateral ureteral obstruction. Kidney Int 1998, 54: $110-119$

27. Doctor RB, Chen J, Peters LL, Lux SE, Mandel LJ: Distribution of epithelial ankyrin (Ank3) spliceoforms in renal proximal and distal tubules. Am J Physiol 1998, 274:F129-F138

28. Zheng G, Zheng L, Wang Y, Wu H, Kairaitis L, Zhang C, Tay YC, Alexander SI, Harris DC: NK cells do not mediate renal injury in murine adriamycin nephropathy. Kidney Int 2006, 69: $1159-1165$

29. Mori K, Lee HT, Rapoport D, Drexler IR, Foster K, Yang J, SchmidtOtt KM, Chen X, Li JY, Weiss S, Mishra J, Cheema FH, Markowitz G, Suganami T, Sawai K, Mukoyama M, Kunis C, D’Agati V, Devarajan P, Barasch J: Endocytic delivery of lipocalinsiderophore-iron complex rescues the kidney from ischemiareperfusion injury. J Clin Invest 2005, 115:610-621

30. Agiostratidou G, Hulit J, Phillips GR, Hazan RB: Differential cadherin expression: potential markers for epithelial to mesenchymal transformation during tumor progression. J Mammary Gland Biol Neoplasia 2007, 12:127-133

31. Fan JM, Ng YY, Hill PA, Nikolic-Paterson DJ, Mu W, Atkins RC, Lan HY: Transforming growth factor-beta regulates tubular epithelial-myofibroblast transdifferentiation in vitro. Kidney Int 1999, 56:1455-1467

32. Heidrich HG, Kinne R, Kinne-Saffran E, Hannig K: The polarity of the proximal tubule cell in rat kidney: different surface charges for the brush-border microvilli and plasma membranes from the basal infoldings. J Cell Biol 1972, 54:232-245

33. Forbes MS, Thornhill BA, Chevalier RL: Proximal tubular injury and rapid formation of atubular glomeruli in mice with unilateral ureteral obstruction: a new look at an old model. Am J Physiol Renal Physiol 2011, 301:F110-F117

34. Nakhoul N, Batuman V: Role of proximal tubules in the pathogenesis of kidney disease. Contrib Nephrol 2011, 169:37-50

35. Sato M, Muragaki Y, Saika S, Roberts AB, Ooshima A: Targeted disruption of TGF-beta1/Smad3 signaling protects against renal tubulointerstitial fibrosis induced by unilateral ureteral obstruction. J Clin Invest 2003, 112:1486-1494

36. Li M, Krishnaveni MS, Li C, Zhou B, Xing Y, Banfalvi A, Li A, Lombardi V, Akbari O, Borok Z, Minoo P: Epithelium-specific deletion of TGF-beta receptor type II protects mice from bleomycininduced pulmonary fibrosis. J Clin Invest 2011, 121:277-287
37. Fukuda K, Yoshitomi K, Yanagida T, Tokumoto M, Hirakata H: Quantification of TGF-beta1 mRNA along rat nephron in obstructive nephropathy. Am J Physiol Renal Physiol 2001, 281:F513-F521

38. Zhang F, Tom CC, Kugler MC, Ching TT, Kreidberg JA, Wei Y, Chapman HA: Distinct ligand binding sites in integrin alpha3beta1 regulate matrix adhesion and cell-cell contact. J Cell Biol 2003, 163: $177-188$

39. Chartier NT, Laine M, Gout S, Pawlak G, Marie CA, Matos P, Block MR, Jacquier-Sarlin MR: Laminin-5-integrin interaction signals through PI 3-kinase and Rac1b to promote assembly of adherens junctions in HT-29 cells. J Cell Sci 2006, 119:31-46

40. Zhang W, Alt-Holland A, Margulis A, Shamis Y, Fusenig NE, Rodeck U, Garlick JA: E-cadherin loss promotes the initiation of squamous cell carcinoma invasion through modulation of integrinmediated adhesion. J Cell Sci 2006, 119:283-291

41. Morini M, Mottolese M, Ferrari N, Ghiorzo F, Buglioni S, Mortarini R, Noonan DM, Natali PG, Albini A: The alpha 3 beta 1 integrin is associated with mammary carcinoma cell metastasis, invasion, and gelatinase B (MMP-9) activity. Int J Cancer 2000, 87:336-342

42. Perl AK, Wilgenbus P, Dahl U, Semb H, Christofori G: A causal role for E-cadherin in the transition from adenoma to carcinoma. Nature 1998, 392:190-193

43. Kavvadas P, Kypreou KP, Protopapadakis E, Prodromidi E, Sideras P, Charonis AS: Integrin-linked kinase (ILK) in pulmonary fibrosis. Virchows Arch 2010, 457:563-575

44. Zhang Y, Ikegami T, Honda A, Miyazaki T, Bouscarel B, Rojkind M, Hyodo I, Matsuzaki Y: Involvement of integrin-linked kinase in carbon tetrachloride-induced hepatic fibrosis in rats. Hepatology 2006, 44:612-622

45. Dedhar S: Cell-substrate interactions and signaling through ILK. Curr Opin Cell Biol 2000, 12:250-256

46. Serrano I, McDonald PC, Lock FE, Dedhar S: Role of the integrinlinked kinase (ILK)/Rictor complex in TGFbeta-1-induced epithelial-mesenchymal transition (EMT). Oncogene 2013, 32:50-60

47. Dai C, Stolz DB, Bastacky SI, St-Arnaud R, Wu C, Dedhar S, Liu Y: Essential role of integrin-linked kinase in podocyte biology: bridging the integrin and slit diaphragm signaling. J Am Soc Nephrol 2006, 17:2164-2175

48. Humphreys BD, Lin SL, Kobayashi A, Hudson TE, Nowlin BT, Bonventre JV, Valerius MT, McMahon AP, Duffield JS: Fate tracing reveals the pericyte and not epithelial origin of myofibroblasts in kidney fibrosis. Am J Pathol 2010, 176:85-97

49. Iwano M, Plieth D, Danoff TM, Xue C, Okada H, Neilson EG: Evidence that fibroblasts derive from epithelium during tissue fibrosis. J Clin Invest 2002, 110:341-350

50. Zeisberg EM, Potenta SE, Sugimoto H, Zeisberg M, Kalluri R: Fibroblasts in kidney fibrosis emerge via endothelial-to-mesenchymal transition. J Am Soc Nephrol 2008, 19:2282-2287

51. Li J, Qu X, Yao J, Caruana G, Ricardo SD, Yamamoto Y, Yamamoto H, Bertram JF: Blockade of endothelial-mesenchymal transition by a Smad3 inhibitor delays the early development of streptozotocin-induced diabetic nephropathy. Diabetes 2010, 59: $2612-2624$ 